\title{
Voices and noises in the theory of speech acts
}

\author{
Savas L. Tsohatzidis \\ Aristotle University of Thessaloniki
}

Günther Grewendorf and Georg Meggle (eds), Speech Acts, Mind and Social Reality: Discussions with John R. Searle. Dordrecht: Kluwer Academic Publishers, 2002, viii+327 pages. ISBN 1-4020-0853-8

Daniel Vanderveken and Susumu Kubo (eds), Essays in Speech Act Theory. Amsterdam: John Benjamins, 2002, vi + 328 pages. ISBN 90-272-5093

\section{Introduction}

The present essay reviews two recent collective volumes on speech acts and related topics: Speech Acts, Mind and Social Reality: Discussions with John R. Searle, edited by Günther Grewendorf and Georg Meggle, hereafter abbreviated as G\&M, and Essays in Speech Act Theory, edited by Daniel Vanderveken and Susumu Kubo, hereafter abbreviated as V\&K. Section 2 of the essay is devoted to G\&M, while Section 3 is devoted to V\&K.

Though different in important respects, the two volumes have a common feature that imposes a clear restriction on the scope of the present review, namely, that (contrary perhaps to what some of their readers might be expecting or wishing) neither of them aspires to offer a comprehensive view of different approaches to fundamental issues of speech act theory (of the sort that was attempted in Tsohatzidis 1994 a decade ago), and neither of them endeavors to establish systematic contact with innovative contemporary research in the theory of meaning that is either directly couched in speech act theoretic terms (see, for example, the approach developed in Alston 2000) or indirectly draws on speech act theoretic notions (see, for example, the approach summarized and expanded upon in Brandom 2000). This fact does not make either volume 
an appropriate occasion for in depth discussion of general issues of speech act theory or of its place within the theory of meaning, and the remarks to follow will accordingly have to be more narrowly focused.

The main difference between the volumes, as far as the present appraisal of them is concerned, is that the first has a unifying, if complex, theme, is moderately well edited, and contains a not insignificant number of valuable papers, whereas the second does not appear to have a unifying theme, is very inadequately edited, and contains a large number of papers whose significance is at best unobvious and at worst non-existent. In the separate presentations that follow, the emphasis will be on evidence supporting the above comparative characterization, though incidental suggestions concerning the treatment of some of the issues raised by individual papers will also be offered. Unless otherwise indicated, parenthetical page references in Section 2 are to G\&M, and parenthetical page references in Section 3 are to V\&K.

\section{Remarks on G\&M}

The G\&M volume assembles papers descending from a 1999 Bielefeld colloquium on the philosophy of John Searle, and, as its title indicates, it includes essays in all three of the main research areas to which Searle has made significant contributions: philosophy of language, philosophy of mind, and social ontology. The book's corresponding three core parts (entitled, respectively, 'Speech Acts', 'Mind' and 'Social Reality') contain eighteen original essays, of which eight are allocated to the philosophy of language part, five to the philosophy of mind part, and five to the social ontology part.

The three core parts are preceded by a part called 'Introduction', and followed by a part called 'New perspectives'. The 'Introduction' part consists of a paper by Searle ("Speech acts, mind and social reality") in which he gives a very brief outline of his published work in the three research areas to which the volume is dedicated. (This paper is followed by the transcript of a short conversation between Searle and Ralf Stoecker, in which Searle repeats some of the points made in the paper, and briefly clarifies some others). The 'New perspectives' part consists of a second paper by Searle ("The classical model of rationality and its weaknesses"), which provides a glimpse of his recent (and, at the time of the colloquium, unpublished) work on the latest of his philosophical interests, the theory of rational action.

Although the editors' idea of asking Searle to contribute an opening and a 
closing paper to a volume of essays devoted to his philosophy was, in itself, obviously appropriate, the degree to which these particular opening and closing papers actually enhance the volume's coherence or originality is minimal. The opening paper will probably be unnecessary for readers already acquainted with Searle's major works, and it will certainly be insufficient for readers wholly unacquainted with those works. Perhaps, then, its intended beneficiaries are primarily readers who happen to be familiar with only one of the three areas of Searle's philosophical interest and who want to know both what his distinctive positions in the remaining two areas are and how his central claims in each one of the three areas impose constraints on the evaluation of his contributions to the other two. The opening paper, however, is far too brief to allow such readers to form an informed opinion on these matters, and Searle is obviously justified when he disarmingly declares, toward the end of the paper, "I do not wish any critic of my views to suppose that this brief summary (...) could be a target for a critical assessment of my work" (p. 16). In any case, Searle has already published a short introductory book, Mind, Language and Society (Searle 1999), whose purpose is precisely to provide interconnected and detailed summaries of his contributions to the philosophy of language, to the philosophy of mind and to social ontology, and that book (whose study might be supplemented with the study of the Searlian interviews published in Faigenbaum 2001) could serve the needs of wholly or partly unfamiliar readers much more usefully than the volume's opening paper (which actually reads, for the most part, like an extended table of contents of Searle's introductory book). As for the volume's concluding paper, it might have been interesting, at the time of the colloquium, to hear Searle launching some of his then unpublished theses on the idea of rationality, but these theses, together with the theoretical framework within which their significance could be best understood and assessed, have in the meantime become available in his book Rationality in Action (Searle 2001), published one year before the G\&M volume, and it is obviously to that earlier book rather than to the volume's concluding paper (which simply reproduces part of the earlier book's first chapter) that interested readers should direct themselves.

Searle's opening and closing papers contain no trace of a response to the various queries, comments and criticisms addressed to him by the authors of the eighteen papers that form the main body of the volume. This is disappointing, and does not help the volume compare favorably with the only previous collective work of similar scope, John Searle and his Critics (Lepore and Van Gulick 1991), which not only contains some high-powered critical essays on 
various aspects of Searle's philosophy, but also includes Searle's detailed replies to each one of his critics. The editors cannot, of course, be held responsible for Searle's unwillingness to respond in print to any of the colloquium papers; it would appear to belong to their responsibilities, however, to ensure two things: first, that prospective readers do not acquire the false impression that the volume does include such responses; and second, that prospective readers receive some introductory information as to what the content of each one of the eighteen papers is, and how it purports to advance our understanding of its chosen topic. Unfortunately, neither of these responsibilities has been assumed. On the one hand, the volume is subtitled Discussions with John R. Searle, even though it contains absolutely no instance of Searle discussing with any of the contributors any of the points that they raise. On the other hand, the editors do not supply any kind of introduction outlining what each of the eighteen papers is attempting to do, or how their individual aims are connected both to each other and to Searle's work, and they do not even equip the volume with an index that some readers might wish to use in trying to trace such connections for themselves. Perhaps, then, the only credit that the editors would expect to be given, as far the presentation of the volume is concerned, is that they have ensured, first, that it is generally free of typographical errors and, second, that the language of those of its contributors who are not native speakers of English, is, though not always idiomatic, almost always comprehensible.

The quality of the papers in the volume's three core parts is variable, though those that are worth at least one reading constitute the majority. I will first go briefly through the papers in the 'Mind' and 'Social Reality' parts, which together take up roughly half of the volume's space, and then turn to the papers in the 'Speech Acts' part, which occupy the other half.

The 'Mind' part consists of an uncharacteristically unfocused paper by Avrum Stroll, a useful essay by Wolfgang Lenzen, a solid contribution by Martine Nida-Rümelin, a largely irrelevant essay by Thomas Bartelborth and Oliver Scholz, and a minimally relevant but maximally presumptuous paper by Thomas Roeper. The purpose of Stroll's paper ("Identification and misidentification") is to examine whether Searle has succeeded, in Intentionality (Searle 1983), to defend his internalist account of mental and linguistic content against the externalist challenges arising from the so-called 'new theory of reference', especially as the latter has been developed in Hilary Putman's early work on the semantics of proper names and natural kind terms (Putnam 1975). Stroll claims, in effect, (a) that Searle has successfully defused the externalist challenges as far as proper names are concerned, (b) that he cannot defuse the exter- 
nalist challenges as far as certain natural kind terms are concerned, and (c) that Putnam's own externalist account of certain other natural kind terms is itself problematic. Claim (a) is not, given the present state of the debate on proper names, developed satisfactorily: Stroll simply declares himself convinced that Searle has successfully defended his internalist account of proper names against externalist challenges, but he fails to discuss, or even to mention, the very detailed, and thoroughly negative, externalist examination of the Searlian arguments by Devitt (1990), and makes no attempt to produce any new arguments in favor of Searle's position that might be considered capable of neutralizing Devitt's critique. Besides, the paper does not mention a paper by Stroll himself where Searle's account of proper names is explicitly claimed to rest on an assumption that, independently of one's position on the internalist/ externalist dispute, is untenable (see Stroll 1998 and the reiteration of that claim in Chapter 8 of Stroll 2000), and this risks creating the inaccurate impression that Searle's account of proper names is actually acceptable to Stroll as it stands. Claim (b) is convincingly argued, though the assumption that there are people who would need to be convinced - that is, people who would believe that Searle has any sufficiently articulated account of natural kind terms, let alone one that could accommodate externalist challenges - appears to be unwarranted. Claim (c), which (judging from the amount of space devoted to it) seems closest to Stroll's interests, is, though quite important in itself, not exactly pertinent as stated, and thus potentially misleading: The full basis of that claim is to be found in previous writings of Stroll's that, again, he doesn't cite (see Stroll 1989 and the subsequent elaboration of that paper's ideas in Chapter 8 of Stroll 2000), in which he argues, on the one hand, that the 'scientistic' version of externalism associated with Putnam's early work provides an inadequate account of certain natural kind terms, and, on the other hand, that a non'scientistic' version incorporating recognizably Wittgensteinian elements would supply a more adequate overall account of such terms. (For a general proposal as to how externalist and Wittgensteinian accounts of mental or linguistic content might be combined, see McCulloch 1995.) The Wittgensteinian direction that Stroll adopts in these writings may indeed be the most promising, but, as his present paper fails to make clear, it could hardly be a comforting direction for Searle to take, since the absolute internalism about content that Searle espouses is as far removed form early Putnamian 'scientistic' externalism as it is removed from late Wittgensteinian anti-'scientistic' externalism. It seems to me, then, that Stroll's contribution has been a missed opportunity to fully articulate one important family of problems that the 
Searlian account of content in Intentionality faces.

The papers by Wolfgang Lenzen and by Martine Nida-Rümelin examine aspects of those of Searle's contributions that are situated at the interface of the philosophy of mind and the philosophy of psychology. Lenzen's paper ("Intrinsic intentionality") is primarily a critical evaluation of some aspects of the socalled Chinese Room Argument that Searle presented in Searle (1980) and then in Minds, Brains and Science (Searle 1984) as part of his many-sided attack on computational theories of mind. Lenzen does not attempt to survey the extensive critical literature that the argument has triggered since its appearance, contenting himself to present his own reasons for, on the one hand, doubting that Searle's argument establishes its intended conclusion and, on the other hand, resisting the tendency of one of its prominent critics, Daniel Dennett, to embrace the negation of its conclusion. (Dennett's tendency to embrace the negation of the argument's conclusion incorrectly assumes, according to Lenzen, that a computational account of the role of emotion in cognition is possible, whereas Searle's original defense of the argument incorrectly assumes that a computational account of the role of perception in cognition is not possible.) Lenzen's interesting arguments against both Searle and Dennett are clearly presented and make his paper a useful addition to a complex debate, though neither the complexity nor the current state of that debate are reflected in its pages. (Interested readers might wish to consult the recent collection, Views into the Chinese Room (Preston and Bishop 2002), which records the latest reflections on the topic both by Searle himself and by many of his most important critics.) Nida-Rümelin's paper ("Causal reduction, ontological reduction, and first-person ontology") is a critical examination of some central features of the account of consciousness that Searle has presented in The Rediscovery of the Mind (Searle 1992), and which he has subsequently used as a basis for his attacks on alternative approaches to the subject in The Mystery of Consciousness (Searle 1997). The main critical target of the paper is Searle's claim that, since the first-person ontology of consciousness is a trivial byproduct of definitional practices, there is no real tension between his thesis that consciousness is causally reducible to neurobiological processes and his thesis that consciousness is ontologically irreducible to neurobiological processes. After carefully distinguishing three separate claims that Searle conflates in his statement of the causal reducibility thesis, and having explained the reasons why causal reducibility claims are generally thought to be seriously undermined by arguments for the explanatory opacity of consciousness due to Chalmers (1996) and to Levine (2001), the paper argues that the ontological irreducibility 
thesis is both non-trivially true and actually inconsistent with all versions of the causal reducibility thesis, and that, therefore, the causal reducibility thesis must, contrary to what Searle intended, be abandoned. Among the high points of the discussion leading to that conclusion are, first, a convincing demonstration that Searle's denial that his position is vulnerable to the explanatory opacity arguments depends on an illegitimate confusion between questions of conceptual necessity and questions of nomological necessity, and, secondly, a painstaking reconstruction and refutation of Searle's argument that the first-person ontology of consciousness is a by-product of definitional practices. The paper is, in my view, one of the most penetrating among the available critical discussions of Searle's views on consciousness, and the most significant contribution to the 'Mind' part of the volume.

The remaining two papers in the 'Mind' part of the volume belong to the uncomfortable genre of colloquium papers that are only tenuously related to a colloquium's theme and merely use that theme as an excuse for publicizing their authors' research agendas. The paper by Thomas Bartelborth and Oliver Scholz ("Understanding utterances and other actions") is primarily a vehicle of its authors' intention to argue that the unbridgeable gap that many philosophers have claimed to perceive between explanations in the natural sciences and explanations in the social sciences is non-existent, and that the idea that both kinds of explanation aim at the maximization of coherence is the key to their unification. The connection with Searle is purportedly established in the paper's closing pages, where his analysis of metaphorical utterances is briefly summarized and heavily praised (without regard to any of the numerous criticisms that it has received) as an analysis that, allegedly, can be easily reinterpreted in coherence theoretic terms. The authors' limited familiarity with Searle's work is evident from the fact that, although their primary purpose is to rebut arguments claiming that natural science explanations and social science explanations cannot be unified, they obviously ignore, and therefore do not discuss, the long series of original arguments that Searle has produced in favor of the thesis that the two types of explanation cannot, for logical reasons, be unified (see especially Searle 1991). Since these arguments directly contradict the authors' unification proposal, not discussing any of them in a volume specifically devoted to Searle's philosophy makes it difficult to figure out in exactly what sense this paper is supposed to be a relevant contribution to the volume's topic. As for the notion of coherence that, irrespective of the volume's topic, the authors are interested in promoting as a kind of all-purpose conceptual problem-solver, it is too vaguely presented in the paper to allow any 
conclusions about its possible value, and the most detailed models of it that are presently available are left unexplored. (It is remarkable, for example, that, although Paul Thagard is named as the authors' authority on coherence, no use is made of the distinctions introduced or of the analyses offered in his main work on the subject, Coherence in Thought and Action (Thagard 2000), whose content is actually in tension with the authors' remarks on metaphorical interpretation as a procedure aiming at explanatory coherence, since, according to Thagard, what motivates metaphorical interpretation is primarily a search for analogical rather than for explanatory coherence.) It seems to me, then, that the Barthelboth and Scholz paper is of no obvious interest to students of Searle, and of only marginal interest to students of either coherence or metaphor, though it might possibly be of some interest to students of some of the other topics that it briefly discusses (ceteris paribus laws, interpretational charity, rationalizing explanation, etc).

I doubt, however, that serious students of any topic could develop an interest for the paper by Thomas Roeper ("The hidden algebra of the mind from a linguistic perspective"), which concludes the 'Mind' part of the volume. Roeper is a linguist working within the Chomskyan tradition, who appears to have been disturbed by the perceived implications of an important new argument against computational theories of mind, much more radical than the Chinese Room Argument, that Searle first presented in Searle (1990) and later used in The Rediscovery of the Mind (Searle 1992). The relevant part of the argument is to the effect that since any physical phenomenon whatsoever admits of a computational description, and since no computational description assigns, as such, an intrinsic, as opposed to an observer-relative, property to the phenomenon it characterizes, no account of mental (including linguistic) phenomena will be scientifically adequate if it ignores the neurobiological and restricts itself to the computational level. If this argument is sound, its implications for the self-image of much of cognitive science (and, of course, of Chomskyan linguistics) are obviously negative. Roeper, however, has chosen, instead of seriously confronting the argument (as others have attempted to do), to try to exorcise it by emitting an obviously uncontrollable series of irrelevant remarks, among which the most comical appear to derive from his idea that Chomskyan linguists need not be worried by the fact that some of their claims are incompatible with Darwinian biology because, according to Roeper, it can be established by moral (!) arguments that Darwinian biology is scientifically inadequate (!). We are given to understand, for example, that Darwinian biology has a serious problem as a theory because (allegedly) "the parent who 
slaps a child while muttering, 'you little monkey', has been influenced by Darwinist theory" (p.224), and, even more dramatically, that the scientific validity of Darwinian biology is doubtful because the "concept of fitness" developed in one of its "inevitable" theoretical extensions has been (allegedly) responsible for such phenomena as "the Third Reich or ethnic cleansing in Kosovo" (p.224). We are also informed that the only form of biology worth having is the one in which the pre-Darwinian concept of teleology is restored as the central explanatory concept, and that the best contemporary attempts at resurrecting such a pre-Darwinian biology are embodied in "Carl Sagan's claims that there should be life in other planets" (p.225) as well as in "the notion of Universal Grammar introduced by Chomsky" (p.225). And we are finally given a list of urgent research problems that a fully resurrected preDarwinian biology should, according to Roeper, be in a position to solve, among which one of the most prominent is, it appears, the problem of "find[ing] a way to state that the musical properties of Mozart are part of the definition of fingertips" (p.227). Subscribing to the author's statement that "dignity is the core of our sense of the self" (p.223), I shall not comment on his paper any further. It seems to me, however, that the volume's editors would owe their readers a note explaining why and how their evaluation procedures have been relaxed in order to accommodate the paper in an otherwise serious volume.

The five papers in the 'Social Reality' part of the volume are all concerned with aspects of Searle's book The Construction of Social Reality (Searle 1995), which constitutes his main contribution to date to the relatively new field of the analytic study of social ontology. Since all the papers express sympathy for the central motivating assumption of that book (the assumption, namely, that, because social reality exists only in so far as it is believed to exist, and therefore is not ontologically objective, the main philosophical problem that it raises is how objective knowledge of it is possible), it should perhaps be noted that the sympathy is by no means universally shared, and that readers wishing to acquire a more realistic view of the reception of Searle's work in this area would do well to consult additional sources. (A good starting point would be the collective volume on John Searle's Ideas about Social Reality (Koepsell and Moss 2003), which reprints very recent critical discussions of Searle's social ontology, among which some - in particular, Viskovatoff 2003 and Fitzpatrick 2003 - express much deeper worries about Searle's project than any of the worries manifested by the present volume's contributors; among earlier discussions, Ruben 1997 and Wettersten 1998 should also be consulted.) In spite of their fundamental sympathy for Searle's project, however, the five papers in the 'Social Reality' 
part express several reservations, many of them justified, either about the way in which Searle attempts to embed his project into wider ontological disputes (in particular, the realist/anti-realist dispute), or about the conceptual resources that he utilizes in order to implement it (in particular, about the three fundamental concepts - collective intentionality, function assignment, and constitutive rule - that he uses in constructing definitions of social notions, and about the relation between these concepts and his concept of the Background).

David Sosa's very short paper ("True reality and real truth") concentrates on Searle's claim that physical, as opposed to social, reality is not belief-dependent, and notes that the way Searle uses that claim as a point of entry into the realist/anti-realist dispute suffers both from crucial ambiguities and from certain mischaracterizations of both the realist and the anti-realist positions in that dispute. Stanley Barry Barnes's paper ("Searle on social reality") offers a typically constructivist discussion of that same claim of Searle's, arguing that, although social reality is indeed, as Searle proposes, entirely belief-dependent, it is not the case that physical reality is, as Searle assumes, belief-independent. (Barnes seems either unwilling to admit or unable to realize that his arguments, if sound, lead to a form of generalized anti-realism, and that, since Searle certainly rejects any form of generalized anti-realism, his position is much more at odds with Searle's than he professes). Josef Moural's paper ("Searle's theory of institutional facts") gives a useful outline of the Searlian account of the subset of social facts that Searle labels 'institutional facts', argues convincingly that, on some important points of detail (for example, the use of negation in the representation of events of institutional fact termination), Searle's account is inadequate, and assembles considerable textual evidence suggesting that there is a fundamental tension between Searle's explicitly representationalist analysis of the conditions of existence of institutional facts in terms of the collective assignment of status functions through constitutive rules and his explicitly antirepresentationalist account of the conditions of existence of institutional facts in terms of the notion of the Background. (Moural does not comment either on the sources or on the consequences of that tension; interested readers might wish to note that much the same tension has been independently detected, and richly commented upon from various perspectives, in four recent papers on Searle - Turner 1999; Dreyfus 2001; Viskovatoff 2002; Thalos 2003 - that virtually pick up the discussion at the point where Moural leaves it). Raimo Tuomela's paper (“Searle, collective intentionality, and social institutions") also comments on Searle's analysis of institutional facts, mainly from the point of view of Tuomela's own theory of social institutions, whose highly compressed 
exposition appears to be the main goal of the paper. (A more leisurely statement of that theory is available in Tuomela's book Philosophy of Social Practices (Tuomela 2002), which is not cited in the paper, but is the source of most of its material.) Tuomela's two main criticisms of Searle - namely, that his account fails to recognize social institutions that are merely based on mutual expectations rather than on mutual agreements, and that it fails to recognize social institutions that merely generate conceptual rather than deontic powers - are not developed in great detail, but they do seem to identify genuine issues that Searle's account of social reality would, in the long run, have to face (even though Searle might conceivably attempt to postpone discussion of these issues, by claiming that the social phenomena that Tuomela considers are not properly called institutional, and should be given a different sort of treatment). Finally, Georg Meggle's paper (“On Searle's collective intentionality") compares and contrasts the way in which Searle defines the notion of collective intentionality in his account of social facts with the more standard ways in which that notion is defined in alternative accounts of social facts within analytic studies of social ontology. (Very roughly, a group's collective intentionality reduces, according to the standard accounts, to each group member's forming a certain 'I'-intention that is the object of mutual knowledge or belief, whereas, according to Searle, a group's collective intentionality reduces to each group member's forming a certain primitive 'we'-intention distinct from any ' $\mathrm{I}$ '-intentions, and not required to be the object of mutual knowledge or belief; for recent discussions of both positions, see the relevant contributions to the volume Social Facts and Collective Intentionality (Meggle 2002)). Some of Meggle's critical remarks on Searle are tendentious. (For example, his claim that Searle's views can be demonstrated to have the absurd implication that "any state of affairs is a social fact" (p.265) depends on, among other things, the assumption that, according to Searle, when P is a social fact, the collective belief sustaining it is not necessarily the collective belief that $\mathrm{P}$, but may be a collective belief whose content is wholly independent of $\mathrm{P}$; however, Searle clearly rejects that assumption through his often repeated claim than, in order for a social fact to exist, a collective belief that this very fact exists is always necessary, and so Meggle's purported demonstration turns out to be directed against a view that neither Searle nor anyone else appears to have endorsed.) Nevertheless, some other critical remarks on Searle that Meggle makes are well taken. (For example, he correctly points out that if, as Searle claims, analyses of social facts in terms of mutually held 'I'-intentions have the defect of being infinitely regressive, then his own analysis of social facts in terms of shared 'we'-intentions has exactly the 
same defect, since it is also an analysis that, in order to be maintained, has become infinitely regressive; and he, again correctly, points out that Searle's claim that social cooperation can only be analyzed within a 'we'-based, and not within an 'I'-based, framework is unsuccessful, since it mistakenly assumes that 'I'-based approaches can only appeal to unconditionally and not to conditionally held preferences among group members.)

In general, the contributions to the 'Social Reality' part of the volume usefully identify specific problems that Searle's conception of social ontology should be acknowledged to have to resolve, assuming that its basic orientation is accepted as unproblematic. It is a pity, however, that none of the papers in the volume attempts to systematically examine the relations between Searle's late interest in social ontology and his long standing interest in speech acts, especially since a philosophical approach to speech acts much earlier than Searle's has recently been claimed - see Smith 1990 and the relevant papers in Mulligan 1987 — to have afforded insights unavailable to Searle's approach precisely because, unlike his approach, it was explicitly guided by considerations of social ontology from the very beginning.

Turning to the 'Speech Acts' part of the volume, I shall be brief on the papers by Daniel Vanderveken and by Frank Kannetzky, since neither of them leaves much room for comment: Vanderveken's paper ("Searle on Meaning and Action") is mainly concerned with summarizing either Searle's well known work in selected areas or Vanderveken's less well known, but already published, work in the same areas, and its reliability as a summary is questionable. (Even disregarding such solecisms as the reference to Austin's trichotomy of locutionary, illocutionary and perlocutionary acts as "Austin's trilogy [sic] of locutionary, illocutionary and perlocutionary acts" (p.142), the coherence of the exposition is often quite doubtful. For example, echoing Searle's thesis that "there are not, as Wittgenstein (...) and many others have claimed, an infinite or indefinite number of language games or uses of language" (Searle 1979:29), Vanderveken asserts that "Searle challenged the anti-theoretical position of the second [= later, SLT] Wittgenstein according to whom there are uncountably many different kinds of language use" (p.142); a few pages later, however, Vanderveken affirms that "Wittgenstein and Searle are right to say that it is impossible to construct a theory of all possible kinds of language games" (p. 158, italics added), citing as the basis the anti-theorical view that, allegedly, Wittgenstein and Searle hold Wittgenstein's contention that "there are 'countless kinds' of language games" (p.158); since readers familiar with the relevant texts could easily determine that Searle does not have the contradictory attitudes toward 
Wittgenstein (or toward theory-construction) that these assertions represent him as having, it seems that the only thing the assertions succeed in showing is that Vanderveken has, apparently, not yet decided whether he should side with Searle or with Wittgenstein on the question that clearly divides them; I doubt, however, that learning about Vanderveken's states of indecisiveness would be the primary preoccupation of prospective readers of the G\&M volume.)

As for Kannetzky's paper ("Expressibility, explicability, and taxonomy"), its professed purpose is to articulate a critique of Searle's so-called 'principle of expressibility' (Searle 1969:19-21). It articulates no such critique, however, since it begins by radically misinterpreting the principle as a kind of recipe designed to give us practical help in dealing with situations where utterances "can be misunderstood because of hidden parameters" (p.78), and then irrelevantly claims that we do not, in our everyday dealings as speakers and hearers, need the help that the principle allegedly purports to give us (because, in cases of communicative uncertainty, "we can", as hearers, "simply ask [the speakers] how an utterance is to be understood" (p.79), and, as speakers, help our hearers understand by, for example, employing "analogies or metaphors", or by "using antonyms and negations [in the] hop[e] that the hearer knows them" (p. 78)). (I presume it is obvious that all this, apart from being rather naïve, has nothing to do with Searle's principle of expressibility - which does not mean, of course, that, once properly elucidated, the principle cannot be thoroughly disputed; for an important recent elucidation and critique, see Récanati 2003; for an interesting early discussion, ignored by Kannetzky, see Binkley 1979.)

Of the remaining six papers in the 'Speech Acts' part of the volume, three are devoted to Searle's declarational analysis of explicit performatives, and three discuss more general issues of the theory of speech acts that he has developed in Speech Acts (Searle 1969), Expression and Meaning (Searle 1979), and subsequent works. I will discuss the two groups of papers separately.

Searle developed his declarational analysis of explicit performatives in "How performatives work" (Searle 1989), perhaps the most frequently cited among the articles reprinted in his recent book of collected essays, Consciousness and Language (Searle 2002). The first declarational analysis of explicit performatives, never cited by Searle but much more thoroughly developed than his own, was presented eight years before Searle's article in a book by François Récanati (1981); the analysis was further developed in the expanded English version of that book (Récanati 1987), which Searle similarly never cites. In his article, Searle assumes, following standard practice, that the distinguishing 
feature of a present tense explicit performative utterance of the form "I (hereby) $\mathrm{V}(\mathrm{p})$ " is that, in the right context, its utterance is sufficient for bringing into existence the illocutionary act that its speaker names under " $\mathrm{V}(\mathrm{p})$ ". He opposes, however, both those who (like himself at an earlier time) would take that feature to be a primitive one requiring no explanation, and those who (like himself at a different earlier time) would be tempted to explain it by claiming that the performance, by the speaker of an explicit performative, of the act named under " $\mathrm{V}(\mathrm{p})$ " is a consequence of that speaker's additionally performing the unnamed act of stating that he is performing the act named under " $\mathrm{V}(\mathrm{p})$ ". This unnamed act of stating is indeed performed, Searle now says, but it is itself a consequence of, among other things, the performance of the act named under "V(p)", and so cannot be invoked in explaining why the act named under " $V(p)$ " is performed; rather, the act named under " $V(p)$ " is performed, Searle now believes, as a result of the speaker's performing another unnamed act, the act of declaring that he is performing the act named under "V(p)"; and the task of an analysis of performativity is to show exactly how a speaker's declaring, in the right context, that he is performing an illocutionary act has as a logical consequence his performance, in that context, of that illocutionary act. The central elements of Searle's analysis are, first, that declaring that one performs a given act by means of a given utterance amounts to manifesting the intention to perform that act by that very utterance, and, second, that illocutionary acts have the special property that recognizing a person's manifest intention to accomplish them suffices for that person's accomplishing them; assuming, then, that the literal meaning of "I (hereby) V(p)" is such that its speaker declares that he is performing a certain act named under " $\mathrm{V}(\mathrm{p})$ ", it follows - Searle contends - that, when the act that happens to be named under " $\mathrm{V}(\mathrm{p})$ " is an illocutionary act, the speaker will automatically succeed in performing the act that he names.

The three papers on Searle's declarational analysis of explicit performatives (by Al Martinich, Robert Harnish, and Günther Grewendorf, respectively) are unanimous in rejecting the analysis, but only two among them offer any reasons justifying the rejection. The one that does not is the paper by Martinich ("On the proper treatment of performatives"), whose allegedly critical remarks on Searle belong to the one or the other of two categories: those in which he simply repeats the analysis and then urges us to abandon it just on the grounds that its claims strike him as "completely counter-intuitive" (p.98) or "unintuitive" (p.99), and those in which he actually tries to refute the analysis by arguments that only succeed in revealing his incomplete understanding of it. Two examples 
of the latter category will have to suffice. In voicing his preliminary reservations about Searle's approach, Martinich claims that it does not do justice to the (alleged) fact that "Leave the room is intuitively as performative as I order you to leave the room" (p.94). However, the question whether or not these two utterances are both 'performative' is not a matter of intuition but of definition. On a now rarely used sense of the term 'performative', they are both performative, for the trivial reason that, in that sense, every serious utterance is performative (because, in that sense, an utterance is performative just when its speaker performs some illocutionary act, whether or not he self-ascribes that act). But on the much narrower, and far from trivial, sense of 'performative' that has come to predominate (the sense in which an utterance is performative when its speaker not only performs an illocutionary act but also self-ascribes that act, and which is the only sense in which the terms 'performative' and 'explicit performative' are synonymous), the first of the above utterances is certainly not performative whereas the second certainly is. And since Searle, at the very beginning of "How performatives work", does distinguish the two senses and does state that it is exclusively with performatives in the narrow sense (in other words, with explicit performatives) that his analysis is concerned, it is hard to see how anyone's habit of using the term in the wide sense, which would in any case trivialize the notion of performativity, could count as an argument against Searle's approach. In what appears to be his central objection to Searle, Martinich claims that the declarational analysis of explicit performatives is unsuccessful because it destroys the coherence of the Searlian taxonomy of illocutionary acts, which Martinich unreservedly accepts and affectionately calls "the good old theory" (p.99). His reasoning here is that, since illocutionary acts of all kinds can be performed by means of explicit performative utterances, and since, on the declarational analysis, explicit performatives perform unnamed acts of declaration, all kinds of illocutionary acts would, on the declarational analysis, turn out to be subcategories of the category of declarations. Martinich calls this alleged result of the declarational analysis an "absurdity" (p. 99). However, no such result can be derived from the declarational analysis, except by someone who commits several elementary mistakes, among which the most obvious is that of interpreting the fact that an act A can be a means for the realization of an act B as evidence that B-type acts are species of A-type acts: Just as the fact that one can express a categorical denial by uttering a rhetorical question does not make denials a species of questions, so the possibility of realizing illocutionary acts of all kinds by means of explicit performatives that constitute declarations does not entail that illocutionary acts of all kinds thereby become species of 
declarations. Martinich's central argument against Searle commits that basic mistake, which is really not different in kind from the mistake of supposing that, since one can cause someone to wake up or to fall asleep by singing songs to them, the act-types 'causing someone to wake up' and 'causing someone to fall asleep' are species of the act-type 'singing songs to someone'. But since it is only Martinich and not Searle who commits that mistake, neither Searle's declarational analysis of explicit performatives nor his taxonomy of illocutionary acts are in any way threatened by anything Martinich says about them.

For serious critical discussion of Searle's declarational analysis, readers of the volume should turn to the papers by Robert Harnish and Günther Grewendorf, who in effect defend, respectively, the two kinds of position concerning explicit performatives that Searle implicitly or explicitly discards before arriving at the declarational analysis. Harnish's paper ("Are performative utterances declarations?") claims that the hypothesis, articulated in Bach and Harnish (1979), that speakers of explicit performatives perform the acts they name by way of performing unnamed acts of stating provides a better overall account of the phenomena than Searle's hypothesis that they perform the acts they name by way of performing unnamed acts of declaring. Harnish supports that claim by arguing (a) that the specific objections raised by Searle against the hypothesis of Bach and Harnish (1979) are not valid, and (b) that Searle's own hypothesis, to the extent that its content is clear, rests on dubiously accurate or dubiously consistent assumptions. Some of Harnish's objections to Searle's account of performatives require acceptance of the Bach and Harnish (1979) account, and might, for that reason, fail to convince uncommitted observers. (Such observers might note, for example, that Searle's account, for all its problems, purports to cover all explicit performatives, whereas the Bach and Harnish (1979) account begins by excluding from consideration all kinds of explicit performatives naming so-called 'essentially conventional' illocutionary acts (for the original distinction between 'essentially conventional' and 'not essentially conventional' illocutionary acts, see Strawson 1964); that exclusion, however, makes it highly doubtful whether the Bach and Harnish (1979) account, even if it was unobjectionable within its restricted domain, could be regarded as an alternative to any account which, like Searle's, purports to cover all explicit performatives, especially since the "conditions of adequacy" on accounts of performatives that Harnish outlines at the beginning of his paper nowhere stipulate that adequate accounts should exclude performatives naming so-called 'essentially conventional' illocutionary acts.) However, many of Harnish's arguments against Searle do not presuppose any thesis of Bach and Harnish (1979), and the one among 
them that, to my mind, is the most decisive (namely, the argument to the effect that the declarational analysis cannot consistently maintain its claim that performativity is a consequence of literal sentence meaning and its claim that performative sentences are not ambiguous between a performative and a nonperformative reading) shows compellingly that, if the declarational analysis is to survive, it will definitely have to repudiate the non-ambiguity thesis with which it was explicitly associated by Searle. Besides, Harnish's close attention to Searle's relevant texts reveals that, on many questions that would be crucial to its evaluation (for example, the question as to how Searle's distinction between linguistic and extra-linguistic declarations should be validated) the declarational analysis supplies either no clear answers or no answers whatsoever and that, consequently, its eventual survival would depend not only on the repudiation of theses with which it was explicitly associated but also on the elaboration and defense of distinctions that it assumes but does not justify. For anyone interested in Searle's declarational analysis, then, Harnish's paper would be essential reading, independently of what one's opinion happens to be on the viability of the analysis that Bach and Harnish (1979) propose for the subset of performatives naming so-called 'not essentially conventional' illocutionary acts.

Grewendorf's paper ("How performatives don't work") seems attracted to the idea that performativity is a primitive phenomenon requiring no explanation, although that idea is not explicitly stated but rather suggests itself through the author's proposed elimination of both of the theses on which the current explanatory competitors respectively depend (that is, the thesis that speakers of explicit performatives perform unnamed acts of stating, and the thesis that they perform unnamed acts of declaring). The first of the two main arguments that Grewendorf advances against both theses (and which draws on an observation made by Schiffer (1972) long ago, with different aims) is, in effect, the following: If explicit performatives realized, besides the acts they name, unnamed acts of stating or of declaring, then (for reasons suggested by Schiffer 1972) their full illocutionary forces could not be made explicit; but explicit performatives do make their full illocutionary forces explicit; therefore, explicit performatives do not realize unnamed acts of stating or of declaring. This argument is unsuccessful, since it equivocates on the interpretation of 'full illocutionary force' and clearly begs the question against the views that it purports to rebut: when Grewendorf affirms, in the second premise, that each explicit performative makes its full force explicit, he simply assumes without argument that the only force that an explicit performative carries is the one that it names; but that is precisely what the theorists he wants to oppose dispute, and it is, in any case, 
only by taking the full force of explicit performatives to include unnamed components that one would have any tendency to accept, via Schiffer (1972), what the first premise conditionally affirms, namely, that the full force of explicit performatives, precisely because it always includes unmanned components, cannot be made fully explicit. The second of the two main arguments that Grewendorf advances against the currently competing explanations of performativity is more interesting. Grewendorf notes that all these explanations require interpreting the main verbs of explicit performatives as indicators of propositional content rather than of illocutionary force, and they thus claim to be able to make clear theoretical sense of the idea that what speakers of explicit performatives say is that they perform certain acts that they do in fact perform; according to Grewendorf, however, the only sense in which a speaker of an explicit performative says that he performs a certain act that he performs is Austin's (1962) phatic sense of 'say', which is irrelevant to the determination of propositional content, and not Austin's (1962) rhetic sense of 'say', which would be relevant to the determination of that content; it would seem to follow, then, that all currently competing explanations of performativity rest on incorrect, or at least wholly unmotivated, assumptions as to what the propositional content of explicit performatives is. This interesting argument would require, in order to be convincing, much more development than it actually receives in the paper. For one thing, the author should at least mention a well known paper by Searle (1968), where Austin's notion of a locutionary act, relative to which the phatic/rhetic distinction is defined, is rejected. For another thing, and most importantly for his purposes, he should both mention and use several studies that have tried either to defend Austin's notion of a locutionary act (and so, the phatic/rhetic distinction) against Searle's objections - see especially Thau 1972, Forguson 1973, Frye 1976 - or to explore various (and not always congruous) directions in which Austin's unsystematic statements about locutionary acts (and their phatic and rhetic components) could be developed in order to become reliable analytical tools — see, for example, Griffiths 1969; Furberg 1971; Strawson 1973; Holdcroft 1978; Récanati 1980. Even in the absence of such developments, however, Grewendorf's argument points to a real issue whose examination is largely neglected in current discussions of explicit performatives, and might turn out to be important in evaluating purported explanations of them.

Though a thorough examination of Searle's declarational analysis would obviously be out of place here, let me conclude this part of the discussion by noting two important, and - as far as I know - previously undiagnosed, 
dilemmas that Searle's conception of performatives yields when combined with certain other elements of his philosophy of language. The first dilemma is a consequence of the assumption of the declarational analysis that the main verbs of explicit performatives are never indicators of illocutionary force and always indicators of propositional content. That assumption is in direct conflict with Searle's proposal to distinguish between two kinds of semantically relevant operators on sentences, the illocutionary and the propositional ones, since that distinction (which is supposed by him to be logically fundamental) is impossible to maintain except on the assumption that the main verbs of explicit performative sentences are always indicators of illocutionary force and never indicators of propositional content. (For example, saying, as Searle would recommend, that the negation in I promise that I won't come is propositional whereas the negation in I don't promise that I will come is illocutionary presupposes that, in I promise that I will come, the performative verb is an indicator of illocutionary force and not an indicator of propositional content; but that presupposition is inconsistent with the declarational analysis of I promise that I will come, where the performative verb has to be taken to specify the content and not the force of the unnamed act of declaration that is allegedly being performed. Similarly, saying, as Searle would recommend, that the conditional in I predict that, if you want my opinion, he will win is propositional, whereas the conditional in If you want my opinion, I predict that he will win is illocutionary presupposes that, in I predict that he will win, the performative verb is an indicator of illocutionary force and not an indicator of propositional content; but this is inconsistent with the declarational analysis of I predict that he will win, where the performative verb has to be taken to specify the content and not the force of the unnamed act of declaration that is allegedly being performed.) The first dilemma, then, is that Searle must abandon either the particular forcecontent division demanded by his declarational analysis of explicit performatives (and so the declarational analysis itself) or his distinction between illocutionary and propositional interpretations of sentence-forming operators (and so, whatever he thought was the fundamental logical insight afforded by that distinction). The second dilemma derives from the declarational analysis' claim that it succeeds in representing the performativity of explicit performatives as a logical consequence of their literal meaning, by assuming that, in virtue of that literal meaning, their speakers manifest intentions (to perform certain acts) that are guaranteed to be fulfilled as soon as they are recognized to be present. That claim is in direct conflict with the particular kind of intentionalist theory of meaning that Searle has developed (see Searle 1986a and Chapter 6 
of Searle 1983) in opposition to Grice's intentionalist theory (see Grice 1957 and the relevant papers reprinted in Grice 1989), since what crucially distinguishes the two theories is precisely that, on the Gricean theory, meaning intentions are essentially communicative in that they are never fulfilled unless they are recognized to be present, whereas, on the Searlian theory, meaning intentions are not essentially communicative since their fulfillment is independent of whether or not they are recognized to be present. Clearly, however, if, as Searle contends against Grice, the fulfillment of meaning intentions is always recognition-independent, it cannot be the case, as the declarational analysis affirms, that the performativity of explicit performatives derives logically from the recognition-dependent fulfillment of the meaning intentions they convey. The second dilemma is, then, that Searle must either abandon the claim that the performativity of explicit performatives is a logical consequence of their meaning (which was the most distinctive claim of his declarational analysis) or the claim that the fulfillment of meaning intentions is always recognitionindependent (which was the most distinctive claim of the intentionalist theory of meaning that he has developed in opposition to Grice's intentionalist theory). Exactly how, if at all, these dilemmas can be resolved is a complex question requiring separate treatment. But the very fact that they arise shows clearly, I submit, that, far from being a natural development of Searle's conception of linguistic meaning, the declarational analysis is actually a proposal that forces many of the tensions inherent in that conception to come to the surface.

The remaining three papers in the 'Speech Acts' part of the volume (by Andreas Kemmerling, Mark Siebel, and Christian Plunze, respectively) move beyond the topic of performatives, and two among them submit certain aspects of Searle's philosophy of language to some of the most intense critical scrutiny that they have received in the recent literature. The paper by Andreas Kemmerling ("Expressing an intentional state") is not critical of any thesis of Searle's (if one excludes an incidental remark dismissing, not without some evidence, "the whole thing about so called constitutive rules" (p.83)), but concentrates on an unanalyzed notion that Searle often uses, and attempts to offer an analysis of it. The notion in question is that of a person's expressing a mental state without necessarily being in that state, and is frequently used by Searle in his accounts of various kinds of speech acts, in particular expressive speech acts. Presumably because Kemmeling finds the notion interesting in its own right, he is not concerned with the fact that the Searlian accounts of speech acts employing it are multiply flawed (for some of the main reasons, see Tsohatzidis 1993). It is best, therefore, to consider the analysis independently of its past uses or abuses 
within speech act theory, which is what Kemmerling himself does when presenting it. Very briefly, the proposed analysis is to the effect that a person $\mathrm{X}$ expresses, by behaving in way $\mathrm{W}$, a mental state $\mathrm{Y}$ even without being in that state $\mathrm{Y}$, if, and only if, (1) $\mathrm{X}$ is a normal member of a population $\mathrm{P}$ and behaves in way $\mathrm{W}$ under normal circumstances, and (2) it is not synthetically but analytically true that, if a normal member of $\mathrm{P}$ behaves in way $\mathrm{W}$ under normal circumstances, then his behaving in way $\mathrm{W}$ constitutes evidence, within $\mathrm{P}$, of his being in the state Y. I suspect that the analysis would be of no interest to those who would refuse to swallow the unanalyzed concept of normality on which it essentially relies (and which it applies indiscriminately to either persons or circumstances), or to those who, for familiar reasons, would deny that a categorical distinction between analytic and synthetic truths is possible. But even those who would not refuse to make these admittedly large concessions might find the analysis ultimately unsatisfactory. Suppose, for example, that there is a population $\mathrm{R}$ whose members live their entire lives under a dictatorial form of government, and that, in order to avoid persecution, all members of the population, in all sorts of circumstances where the question arises, make it a point to express the belief that their government is democratic, even though not a single one among them really has that belief; on Kemmerling's analysis, it would follow that it is a conceptual truth that the behavior of the population provides evidence to every member of $\mathrm{R}$ that every other member of $\mathrm{R}$ really believes that the government is democratic; but since it can hardly be a conceptual truth that no distinction can possibly be made between epistemic justification and propaganda, it seems that Kemmerling's analysis is mistaken.

The paper by Mark Siebel ("What is an illocutionary point?") begins by noting that, although the notion of illocutionary point is fundamental to Searle's theory of speech acts, Searle has never supplied a definition of that notion, and proposes to examine how such a definition could be constructed on the basis of the definitions of the five illocutionary points underlying Searle's taxonomy of speech acts (Searle 1975), and later used as foundations of his system of illocutionary logic (Searle and Vanderveken 1985). Siebel then shows that no less than four non-equivalent definitions of the notion of illocutionary point can be constructed on that basis, and, furthermore, that each one of these four definitions, when taken in conjunction both with the Searlian taxonomy's stated objectives and with the Searlian analyses of individual illocutionary acts, turns out to be problematic, either because it has the effect of making the proposed analyses of individual speech acts internally inconsistent or because it has the effect of violating the mutual exclusivity requirement on taxonomic 
classes that the taxonomy was aiming to respect. The author summarizes his investigations by expressing the (surely understated) opinion that "it is hard to grasp the point of illocutionary point" (p.138), and the arguments on which his conclusions are based are carefully stated and invariably compelling. Furthermore, the various critical remarks on Searle's taxonomy that he makes on his way to these conclusions are all apposite, and, when combined with the results of some powerful independent critical studies of that taxonomy that he does not mention (in particular, Sadock 1994), establish beyond reasonable doubt that the confidence with which Searle assumes the taxonomy's correctness in both informal and formal expositions of his theory of speech acts is not justified.

Finally, the paper by Christian Plunze ("Why do we mean something rather than nothing?") is a critical analysis, based on an examination of the special but central case of assertive speech acts, of Searle's attempt, already referred to above, to replace Grice's intentionalist theory of meaning with a new intentionalist theory, where the only meaning-constitutive intentions are not Gricean communicative intentions but what Searle calls 'representing intentions' (that is, intentions whose fulfillment is recognition-independent, and whose goal is to impose on not intrinsically intentional physical objects - namely, utterances - conditions of satisfaction held under various illocutionary modes). The author's main conclusion is that Searle has failed to demonstrate that his intentionalist theory is superior to Grice's. That conclusion is based on two series of arguments: (a) those in which Searle's criticisms of Grice are shown to be ineffective either because they are based on counterexamples that are apparent rather than genuine or because they are based on counterexamples that, though genuine, are also counterexamples to Searle's own approach; and (b) those in which Searle's positive account of meaning in terms of 'representing intentions' is shown to be inadequate either because it fails to preserve obvious distinctions or because it has obviously absurd consequences. All the arguments are persuasively deployed, and those, in particular, that are directed against Searle's notion of 'representing intention' belong to the best contemporary discussions of the idiosyncratic version of intentionalism that Searle has tried to develop in the theory of meaning. Indeed, when taken in conjunction with the results of two highly relevant critiques, which Plunze does not mention, of Searle's antiGricean arguments (Bennett 1991 and Siebel 2001), they make it difficult to avoid the conclusion that, if an intention-theoretic account of meaning was to be attempted at all, then the Gricean conception of meaning-intentions would be by far preferable to the Searlian one as a basis of such an account. 
To summarize all the preceding remarks, my opinion on the G\&M volume is, on the whole, positive. Although six out of the eighteen papers that constitute its core suffer from various kinds of serious weaknesses, the remaining twelve papers make interesting, and in some cases important, contributions to the study of their topics. And although neither Searle's unwillingness to contribute a written reply to his critics nor the editors' unwillingness to contribute an introduction to the critics' arguments make the volume an especially impressive sequel to the Lepore and Van Gulick (1991) collection of critical essays on Searle's philosophy, it will be a valuable resource for those interested in all three of the main areas of Searle's philosophical work, especially if used in conjunction both with that earlier collection and with a more recent collection of critical essays on Searle (Smith 2003), which is comparably broad in scope.

\section{Remarks on $\mathrm{V} \& \mathrm{~K}$}

The editors' introduction to the V\&K volume provides brief summaries of the volume's papers, but what it attempts to do beyond that - namely, to offer a "historic [sic] survey" (p. 1) of speech act theory, and to tell readers where "the future of speech act theory lies" (p.18) - should perhaps have been left for another, more mature, occasion. The "historic" [sic] survey turns out to be a catalogue of problems in the theory of meaning that, allegedly, have been fully and definitively solved in a previous book by one of the editors (even though they "were completely ignored" (p.10) by such figures as Aristotle, Frege, Russell, Carnap and Davidson, to mention but a few); and the direction in which "the future of speech act theory lies" is announced to be identical to the direction adopted by the same editor's "recent papers" (p. 18) — which, though not included in the volume, are described in the introduction much more thoroughly than any of the papers that the volume does include. In short, the introduction's primary purpose appears to be to alert the world to the presumed significance of the work on various topics that one of the volume's editors has done in the past; but since that work, whatever its value, has been done elsewhere, it is unclear why the volume's readers should be supposed to be unable to absorb the volume's contents without antecedently becoming convinced of that work's presumed significance. One fact that the introduction does succeed in making clear, no doubt unintentionally, is that readers should perhaps be prepared to encounter many instances of editorial carelessness 
throughout the volume. To give one among many examples: Although the introduction is presented as co-authored by the volume's two editors, it has a footnote reading, "I am grateful to $[\mathrm{x}]$ for $[\mathrm{y}]$ " (p.285), which is uninterpretable except on the metaphysically extravagant assumption that fusions of individuals are possible.

Besides the editorial introduction, the volume contains twelve papers, which, with one exception, have not been previously published. The exception is John Searle's paper "How performatives work", published fifteen years ago (Searle 1989), whose reprinting in the volume is difficult to understand, not only because it is a well known paper easily accessible elsewhere, but also because none of the other papers in the volume enters into any kind of systematic dialogue with it. Of the remaining eleven papers, the one by Daniel Vanderveken is by far the longest in the book. The other ten papers are for the most part thematically disparate and, in the majority of cases, far more narrowly focused than their titles suggest. I will briefly comment on them, following (in the absence of any obviously applicable principle of categorization) the order in which they appear, and will return to Vanderveken's contribution before the conclusion.

The paper by André Leclerc ("Verbal moods and sentence moods in the tradition of universal grammar") is a largely doxographic account of the not always consistent ways in which the question of the semantics of verbal mood was treated in the Port Royal logic and the Port Royal grammar, as well as a description of the different forms in which different elements of the Port Royal tradition have survived in the work on verbal mood by various grammariansphilosophers of the European Enlightenment. No systematic attempt is made either to elucidate the intellectual contexts within which the individual views reported in the paper have been developed or to connect these views to contemporary issues in the analysis of mood. Indeed, some significant recent research that has connected certain Enlightenment conceptions of mood with specifically speech act theoretic issues is not even mentioned. For example, Leclerc expresses the opinion that James Gregory's account of mood "is the most advanced and interesting of all those developed during the Enlightenment" (p. 78). But since the originality of that account is largely due to the fact, noted by Gregory himself and acknowledged by Leclerc, that it incorporates Thomas Reid's distinction between 'solitary operations of the mind' and 'social operations of the mind', one might expect that Leclerc would grasp this opportunity in order to investigate in some detail the use of that distinction in Reid's own philosophy of language. No such investigation is attempted, however, and no reference is 
made to a revealing study (Schuhmann and Smith 1990) that both undertakes such an investigation and shows in some detail that, by insisting that what distinguishes a 'solitary' from a 'social' operation of the mind is that the former can whereas the later cannot exist without being communicated, Reid came close to arriving at what is recognizably a distinctive contemporary position in speech act theory. One might expect that the paper would at least be serviceable as a source of information on aspects of the history of the study of mood for readers who happen not to know French; it cannot, however, be recommended even for that limited purpose, first because none of its numerous, and sometimes lengthy, quotations from French is translated, and secondly because the author's command of English is often quite uncertain (as becomes evident from, for example, the use of "What does mean the view that [x]?" (p.70) instead of 'What does the view that $[\mathrm{x}]$ mean?'; or of "a respectable tentative [sic] to solve some of the problems" (p. 84) instead of 'a respectable attempt to solve some of the problems').

The paper by Candida Jaci de Sousa Melo ("Possible directions of fit between mind, language, and world") devotes most of its nine pages to repeating, on the one hand, Searle's well known four-fold classification of possible 'directions of fit' between linguistic representations and extra-linguistic reality (Searle 1975), and, on the other, Searle's claim that his attempted application of the 'direction of fit' apparatus to the analysis of the relation between mental representations and extra-mental reality has revealed an asymmetry between illocutionary acts and mental states, since, although there are certain illocutionary acts, namely declarations, that impose on their contents the so-called 'double' direction of fit, there are no mental states that impose on their contents the 'double' direction of fit (Searle 1983). The author does not dispute any of Searle's claims (and appears to be unaware of an important study by Humberstone (1992) that is highly critical of the ways in which Searle and others have sought to explicate the notion of 'direction of fit'), but announces that she has made a discovery that to some extent minimizes the asymmetry that Searle had noticed, namely that, although there are indeed no mental states that impose on their contents the 'double' direction of fit, there are certain mental acts, which, just like illocutionary acts of declaration, impose on their contents the 'double' direction if fit. The reader who might at this point have become eager to learn what these mental acts are, and how Searle could have overlooked them, is informed that the mental acts in question are "illocutionary acts of declaration such as inaugurations, appointments, decrees, benedictions, confirmations, definitions [etc]" (p.111). But these, the reader might now feel inclined to 
protest, are the very acts that Searle has already described as imposing on their contents the 'double' direction of fit, without thereby feeling obliged to modify his asymmetry thesis, since, on his account, illocutionary acts are not identical with mental acts. Where exactly, then, does the author's discovery lie? The 'discovery', it transpires, is that, according to the author, and contrary to Searle, each illocutionary acts is identical to a mental act ("illocutionary acts are conceptual acts of thought" (p.111)), and that, therefore, since illocutionary acts of declaration have been described by Searle as imposing on their contents the 'double' direction of fit, they should also be described by him as 'mental' acts imposing on their contents the 'double' direction of fit. The utter triviality of that 'discovery' has obviously failed to amaze the author; her readers, however, are guaranteed to be amazed both by the reasoning that has made the alleged discovery possible and by the implications she has managed to derive from it. Thus, the author's only apparent reason for claiming that illocutionary acts are nothing more than mental acts is that "when we perform them we think" (p.111) — which is about as cogent an argument as the argument that, for example, the act of robbing a bank or the act of escaping from prison are nothing more than mental acts, since, presumably, 'when one performs them one thinks'. And one of the main implications that the author has derived from the 'discovery' that declarations are purely mental acts, and that, therefore, it is immaterial whether or not their occurrence is verbally signaled, is that "nothing prevents us from enriching by declaration the mental 'language of our [sic] thought' (Fodor 1975)" (p. 114) — a claim that, among other things, manifests either complete ignorance or complete misunderstanding of the work cited, since, according to Fodor, if there is such a thing as a 'language of thought', it must be innate, and so it cannot be either 'enriched' or 'impoverished', no matter how many declarations, verbal or 'mental', anyone performs. The overall impression that this paper conveys is that of a mediocre essay by a beginning philosophy student (though some remarks, such as the one according to which smiling is a "propositional attitude" (p.117) would appear to point to a region well below mediocrity, even by student standards). Readers should therefore not be surprised to learn, from the 'Notes on contributors' section at the end of the book, that the author is in fact a student working under the supervision of one of the volume's editors (p.321); they might well be surprised, however, at the supervisor's decision to burden the volume with an apparently unmarked student essay.

Although the paper by Alain Trognon ("Speech acts and the logic of mutual understanding") is ostensibly written in English words, it contains many word 
combinations that are not English sentences (for example, "a complex illocutionary act is comprised of a question and a prohibition" (p. 132)), as well as many word combinations that are not interpretable English sentences (for example, "an assertive is verified in a conversation if the hearer considers it as true of its objective truth" (p.133)), and could relatively safely be recommended only to readers who happen to know French and to have the patience to make guesses as to which French expressions Trognon was trying to translate by putting together English words (thus, a reader who just knows English will not be able to figure out what is meant by the word string "for this reason which it is not possible to prove that the truth of $[\mathrm{x}]$ is a consequence of $[\mathrm{y}]$ ” (p.133); however, if a reader happens to know how to interpret the French phrase 'pour cette raison qu'il n'est pas possible de prouver que la vérité de $[\mathrm{x}]$ est une conséquence de [y]', then he or she will probably be able to understand that what Trognon was trying to express by composing his word string is simply what would be expressed by the English phrase 'because it is not possible to prove that the truth of $[\mathrm{x}]$ is a consequence of $\left.[\mathrm{y}]^{\prime}\right)$. Turning to the paper's substance (to the extent that its substance is discernible in spite of its form), it appears that Trognon's main concern is to show that a certain 'law' of illocutionary logic can, on the assumption that it has been internalized by speakers and hearers, be invoked in order to explain the interpretative phenomena usually discussed under the heading of 'indirect speech acts'. It turns out, however, that Trognon's understanding of illocutionary logic is in no better shape than his understanding of English, and that his proposed application of the 'law' to the few data he considers makes no explanatory sense. To take two of his examples, consider the situation (call it S1) where a speaker A says Do you know where today's newspaper is? and his hearer B reacts by saying I will get it; or the situation (call it S2) where a speaker A says There is a draft and his hearer B reacts by closing a nearby window. The familiar problem that these examples pose is that of explaining how, by the time B's verbal or non-verbal reaction becomes available in S1 or S2, both A and B would be likely to presume that $\mathrm{B}$ has interpreted A's utterance as a request (to get the newspaper or to close the window, respectively), in spite of the fact that A's utterance in S1 or A's utterance in S2 do not linguistically encode the relevant requests. Trognon correctly perceives that (rhetoric to the contrary notwithstanding) conversation analysis is not really in a position to supply an explanation of these facts. However, his own explanation is both indefensible in its presumption to have attained its goal and deeply confused about the means it invokes for attaining that goal. The proposed explanation appears to be this: What makes A's 
utterance in $\mathrm{S} 1$ interpretable as a request for the newspaper, or A's utterance in S2 interpretable as a request for closing the window, is, first, that there is a law of illocutionary logic (presumably known to every speaking human) to the effect that requests, along with certain other types of speech acts, are such that they cannot be satisfied (that is, complied with) unless they are successful; and, second, that, since B's reactions in S1 and S2 would satisfy certain requests if these requests had been made, the speaker and hearer of S1 and S2 are entitled to presume that these requests have been made. Thus, since B reacts in S1 in a way that would satisfy a request for getting the newspaper, if that request had actually been made by $\mathrm{A}, \mathrm{A}$ and $\mathrm{B}$ are both entitled to conclude that $\mathrm{A}$ has actually made that request; and since B reacts in S2 in a way that would satisfy a request for closing the window, if that request had actually been made by $\mathrm{A}$, $A$ and $B$ are both entitled to conclude that $A$ has actually made that request. Now, even superficial acquaintance with the system of illocutionary logic that Trognon uses (Searle and Vanderveken 1985) would be sufficient for realizing that he simply does not understand, among many other things (too many to be detailed here), what "satisfaction" is supposed to mean in that system, since his notion of satisfaction, unlike the notion of satisfaction used in that system, absurdly entails that both a hearer who closes a window because he was requested to do so and a hearer who merely says that he will get the newspaper that he was requested to get 'satisfy' their respective requests. According to both illocutionary logic and common sense, however, only a hearer who is actually doing what he was requested to do, and not a hearer who merely says he will do what he is requested to do, counts as having satisfied - that is, complied with - a request that has been addressed to him. The major problem with Trognon's proposed explanation, however, is independent of his confused understanding of illocutionary logic (which is actually irrelevant to his concerns), and would persist even if we agreed, for the sake of argument, on a disjunctive definition of 'satisfaction', according to which a hearer 'satisfies' a request just in case he either does what he is requested to do or merely says that he will do what he is requested to do. Assuming that interpretation, Trognon's explanation boils down to this: The reason why A's utterances in S1 and S2 are interpreted as conveying certain requests that they do not linguistically encode - in other words, the reason why they are interpreted as conveying certain indirect requests - is that B's verbal or non-verbal reactions in S1 and S2 are such that they would 'satisfy' (in the disjunctive sense of 'satisfaction') these requests, if these requests were actually made. The explanation is totally empty, however, as can be seen from the fact that it fails to specify either necessary or sufficient 
conditions for the occurrence of the phenomenon to be explained. To see that no necessary condition is specified, consider a situation S3 where A says Do you know where today's newspaper is? and B reacts by saying Don't even think I shall get today's newspaper for you, or a situation S4 where A says There is a draft and $\mathrm{B}$ reacts not by closing, but by opening even more widely the window that is obviously implicated in the occurrence of the draft. It is clear that in these situations A's utterances would have been still interpreted as indirect requests (for getting the newspaper or for closing the window, respectively), even though B's reactions could not possibly have been interpreted as satisfying these requests, even in the disjunctive sense of 'satisfaction'. Trognon's explanation, therefore, does not even succeed in specifying a necessary condition on the interpretability of an utterance as an indirect request. And it is clear, of course, that it does not specify a sufficient condition either. Consider, for example, a situation S5 where a speaker A utters the sentence It's a nice day today, and her hearer $B$ reacts by slapping the speaker on her face. Since it is obvious that the sentence It's a nice day today does not linguistically encode a request for a slap, and since it is also obvious that slapping a person on her face would 'satisfy' that person's request for a slap, if that request was actually made, it ought to be the case, if Trognon's explanation specified a sufficient condition, that both A and B would readily interpret the utterance of It's a nice day today in S5 as an indirect request for a slap. Since this is evidently not the case, it appears that the reasons that really account for the fact that certain utterances can, and certain other utterances cannot, be interpreted as indirect requests are totally invisible to Trognon's 'explanation'.

The paper by Steven Davis ("Utterance acts and speech acts") is not primarily a contribution to speech act theory, but rather an attack on Donald Davidson's views on the individuation of events and actions (see the papers collected in Davidson 1980), to the extent that these views imply that, just as, when the turning of a key results in the locking a door, a single event (describable in two different ways) takes place, so, when an utterance act results in an illocutionary act, a single event (describable in two different ways) takes place. (Notice that Davidson's view is only a view about token-identities rather than a view about type-identities.) Davis contends that, by mimicking an argument that Tyler Burge (1979) has long ago produced against the token-identity of brain states and mental states, he can construct an effective argument against Davidson's implied view about the token-identity of utterance acts and illocutionary acts. To roughly summarize, Burge's (1979) argument invites us to consider a given individual X with respect to two possible words, W1 and W2, 
taken to be epistemically inaccessible to each other, of which the first is the actual world and the second is identical to the actual world except for the fact that what is $\mathrm{H}_{2} \mathrm{O}$ in W1 has been replaced in W2 with a substance totally different chemically from, though phenomenologically identical to, $\mathrm{H}_{2} \mathrm{O}$; Burge then asserts that a sentence like $X$ believes that water is good to drink might be true of $\mathrm{X}$ relative to $\mathrm{W} 1$ but could not be true of $\mathrm{X}$ relative to $\mathrm{W} 2$; and he concludes that token brain states are not identical to token mental states, since X's brain states would, by hypothesis, be the same in W1 and W2, whereas X's reported belief would be true in W1 and false in W2. Davis's variation on Burge's argument (which was itself a variation on a popular Putnamian argument), is that, in the setting described by Burge, an utterance-act report like $X$ said "Water is good to drink" would, if true of X, be true of X both relative to $\mathrm{W} 1$ and relative to $\mathrm{W} 2$, whereas an illocutionary-act report like $X$ said that water is good to drink might be true of X relative to W1 but could not be true of $\mathrm{X}$ relative to W2; from which Davis concludes that utterance-acts cannot, contrary to Davidson's implied view, be token-identical with illocutionary acts. The argument is not compelling, however. For one thing, even those who would regard appeals to possible worlds as admissible in philosophical argumentation could easily come up with evidence that runs counter to Davis's central claims. For example, assuming that an inhabitant $\mathrm{X}$ of the world W2 - which, by hypothesis, contains no $\mathrm{H}_{2} \mathrm{O}$ - has produced a token of "Water is good to drink", the conjunctive sentence $X$ said that water is good to drink, but it was not to real water that he was referring would be true rather than false relative to $\mathrm{W} 2$; but this is clearly inconsistent with Davis's claim that the sentence $X$ said that water is good to drink could never be true relative to $\mathrm{W} 2$, and shows that the essentialist assumption dictating that claim - the assumption, namely, that neither "water" nor "real water" could possibly refer to anything other than $\mathrm{H}_{2} \mathrm{O}$ - is, whatever its metaphysical appeal, not necessarily semantically relevant. For another thing, Davidson has repeatedly indicated his reasons for regarding appeals to possible worlds as inadmissible in philosophical argumentation, and it is, therefore, pointless (to say the least) to direct against him arguments crucially depending on the admissibility of possible words without previously answering his many objections of principle against all arguments of this kind. It may be noted, incidentally, that Davis makes no reference to any of the numerous independent discussions defending or attacking Davidson's views of act individuation, thus making it impossible to judge exactly where he stands on the many relevant issues raised by these discussions. And it should also be noted that, perhaps most surprisingly given his ostensible topic, he fails to take 
notice of a study by Robinson (1974) which for the first time attempted to use speech act theoretic materials in testing both Davidsonian and anti-Davidsonian views of act individuation, and has already argued on independent grounds that, at least in their simplest forms, both types of view have difficulties in handling these materials. It seems to me, then, that Davis's paper not only fails to develop a convincing original argument against Davidson's views, but does not even succeed in acquainting its readers with the variety of complex issues that should be addressed by anyone seriously attempting either to oppose or to support those views.

The paper by Tomoyuki Yamada ("An ascription-based theory of illocutionary acts") is a preliminary attempt at developing, on the basis of Devlin's (1991) formalization of situation theory, a notation capable of yielding definitions of illocutionary acts in terms of their context-changing properties, and, most importantly, of capturing identities of propositional content across illocutionary act types without assuming the standard conception of propositions as essentially truth-valuable entities. Though preliminary in character, the formal proposal is convincingly motivated and clearly implemented, thus making Yamada's paper a worthwhile contribution both to situation theory, where questions of illocutionary force are not systematically addressed, and to speech act theory, where the context-changing properties of illocutionary acts, and so their character as acts, is often ignored, while the characterization of their propositional contents standardly takes the facile route of using truththeoretic notions in contexts where their relevance, or even their intelligibility, is questionable.

The paper by Bernard Moulin and Daniel Rousseau ("An approach for modelling and simulating conversations"), is not in any specific sense about speech acts, but its most remarkable feature is that, in spite of its title, it is not in any clear sense about conversation either. What the authors are primarily offering is a series of speculations about the proper design of a mechanical device that would enable the operations executed by two or more robots to be coordinated, and would thus provide, in the authors' view, a simulation of human conversation. In a manner familiar from some other works in artificial intelligence, the authors never explain exactly why the coordinated execution of these operations, assuming it to be mechanically possible, should be deemed to be a simulation of a human conversation. Indeed, they do not even seem overly concerned by the fact, revealed in a footnote (p.292) but studiously obscured in the text, that their robots, though allegedly designed to conduct 'conversations', are not supposed to be either language generation or language recognition 
devices - and, as if that was not enough for doubting that they have a clear conception of what they are trying to model, they describe the phenomena they are interested in modeling as activities where agents "propose [to each other] mental states" and "negotiate about the mental states they propose" (p. 184), without appearing to realize the multitude of category mistakes that this description involves. The authors' underlying idea is, apparently, that, once a device could be constructed that would successfully coordinate the execution of one or more tasks by two or more robots, it would become true by definition that the robots are having a 'conversation' of some sort. But if that was their idea, they should make its purely stipulative character explicit rather than pretend that they have offered a simulation of human conversation just because they have elaborated a complex terminological ritual where the various components of their collection of mechanical devices are given names that might directly or indirectly recall real conversational episodes. Notice, for example, that not only are the robots themselves called "locutor [sic] agents" — in spite of the fact that they are not supposed to either generate or recognize anything linguistic - , but that each of the various parts of the device that would coordinate their performances is supposed to be a separate 'agent' by itself: The part of the device that would record the robots' past reactions to instructions is called "the conversational agent", the part of the device that would encode data about the robots' environment is called "the environmental agent", the part of the device that would determine whether the robots associate the same or different outputs to a given input is called "the discourse manager", and so on. People interested in speculative artificial intelligence may be fascinated by this kind of parody, but I doubt that the paper would have anything to offer to prospective readers of the $\mathrm{V} \& \mathrm{~K}$ volume, assuming that none of these readers would be so gullible as to accept without argument that a mechanism of successful robotic coordination is necessarily a proper model of human conversation. (Prospective readers should also be warned that, though the paper purports to be written in English, its attempted simulation of English does not always produce acceptable results. For example, instead of 'relations like acceptance, denial, etc', the authors write, "relations like acceptation [sic], denial, etc" (p. 187); and instead of (presumably) 'one piece of evidence for that claim is [x]', they write, "an [sic] evidence of [sic] that claim is [x]" (p.184).)

Although its title would appear to promise grander things, the paper by Susumu Kubo ("Illocutionary morphology and speech acts") is about a single verbal affix of Japanese (teyaru), which the author proposes to call an 'illocutionary affix', in the manifest hope of thereby inaugurating a new field of research 
called 'illocutionary morphology'. The author's highly experimental English may make some readers unable to read through the paper (for example, in introducing it, Kubo writes, "This paper will be written on the basis of the philosophical ideas of speech act theory" (p.211, italics added), a statement that may make some readers doubtful as to whether the paper they appear to be reading has or has not been written yet). However, even readers persistent enough to read through the paper will not, as far as I can predict, either acquire a clear understanding of what teyaru is supposed to mean or detect a clear reason for calling it an 'illocutionary affix'. Kubo's first attempt at explaining what teyaru means is the following (p.210): “Teyaru serves to give the hearer the benefit of the act represented in the propositional content by revising and extending the previous analysis given in Kubo (1993)". This explanation should obviously be discarded on a priori grounds, since it implies that the meaning of teyaru makes reference to Kubo's publications. Kubo's subsequent attempts at explaining what teyaru means vacillate between the claim that it is an indicator of speaker status (for example, "teyaru is used in (...) contexts (...) in which the speaker invokes a position of the [sic] authority over the hearer" (p.214)), and the claim that it is an indicator of illocutionary force (for example, "teyaru names either commissive or declarative illocutionary forces" (p.211)). Since Kubo treats these explanations as equivalent, a reasonable hypothesis is that he is actually confusing status indicators with force indicators. That hypothesis is fully confirmed by a footnote, where Kubo writes, "teyaru has the illocutionary meaning, 'the speaker's authority over the hearer"” (p.294) — without, presumably, realizing, that, if the expression 'the speaker's authority over the hearer' names anything at all, it certainly does not name an illocutionary force of any kind, and so cannot be supposed to have an 'illocutionary meaning' in any known sense of that term. Keeping the notions of status indicators and force indicators clearly distinct, one might, nevertheless, examine whether the data actually presented in the paper favor an interpretation of teyaru as a force indicator, in which case Kubo's decision to call the affix an 'illocutionary affix' would be (in spite of his explanations) vindicated, or, on the contrary, favor an interpretation of teyaru as a status indicator, in which case the decision to call it an 'illocutionary affix' would be blatantly unjustified. Upon examination, it turns out that every single instance of the affix's use cited in the paper strongly suggests that teyaru is a status indicator (a hardly surprising result, perhaps, given the omnipresence of status distinctions in Japanese morphology) rather than a force indicator, even though Kubo, always unable to maintain a clear conceptual distinction between status and force indicators, persists in misde- 
scribing it as a force indicator. For example, the explicit performative utterances Ayama-t-teyaru, Kansha-shi-teyaru and Iwa-t-teyaru are respectively glossed (p.214) as 'In my capacity as your superior, I hereby apologize to you', 'In my capacity as your superior, I hereby thank you' and 'In my capacity as your superior, I hereby congratulate you'. Assuming that they are even approximately correct, these glosses make it perfectly clear that, in each case, it is the performative verbal stem rather than the teyaru affix that determines the utterance's illocutionary force, whereas teyaru merely invokes the speaker's presumed 'superior' status relative to the hearer. In spite of this, Kubo describes the above examples as confirmatory of the following 'generalization': “The illocutionary force of an utterance with [the] illocutionary affix teyaru is not that of the matrix verb of the utterance, but that of the illocutionary affix" (p.216). This statement implies that, contrary to what Kubo's own glosses show, the above mentioned performative utterances do not realize the acts of apologizing, thanking and congratulating named by their verbal stems, but rather the hitherto unknown 'illocutionary act' named by teyaru, which, as already noted, Kubo glosses as 'the speaker's authority over the hearer'. Since, however, 'the speaker's authority over the hearer' is not the name of any illocutionary act whatsoever, and since the illocutionary acts of apologizing, thanking and congratulating, which are named in the relevant verbal stems, are certainly performed by the utterances Kubo cites, the only option consistent with Kubo's actual data is that of describing teyaru as a status indicator rather than as a force indicator. And in that case, of course, the whole idea on which the paper rests, namely, that teyaru is a force indicator whose existence would justify the inauguration of a new field of research called 'illocutionary morphology', should obviously be rejected. Exactly where Kubo's confused identification of status indicators with force indicators originates from is difficult to tell, but some remarks (p. 214, p. 215) suggest that it is related to the fact that he has read in Searle and Vanderveken (1985) that there is something called a 'mode of achievement of an illocutionary force', which sometimes refers to authority relations between speakers and hearers as preconditions on the performance of certain illocutionary acts. Obviously, however, Searle and Vanderveken (1985) are not responsible for Kubo's confusions, since, just as a mode of catching a fly is not a fly, so a mode of achievement of an illocutionary force is not an illocutionary force; consequently, the fact that a speaker is or purports to be in a position of authority when performing a given illocutionary act does not, contrary to what Kubo imagines, make positions of authority identical with illocutionary acts. 
Although one wouldn't suspect it from its title, the paper by Masa-aki Yamanashi ("Speech act constructions, illocutionary forces and conventionality") is mainly about compatibility constraints on quoting verbs and quoted utterance types in contexts of direct quotation. The paper assumes no theory of quotation whatsoever, and so it is unobvious exactly what the significance of its claims could be supposed to be, even if they were true. Besides, to the extent that the claims are both clear and non-trivial, they do not appear to be true. The one among them that is least unclear and arguably non-trivial can be formulated as follows: If an utterance is an indirect but conventionalized way of performing a given illocutionary act, then that utterance can be introduced in a context of direct quotation by a verb naming the illocutionary act in question, whereas if an utterance is an indirect but non-conventionalized way of performing a given illocutionary act, then it cannot be introduced in a context of direct quotation by a verb naming the illocutionary act in question. For example, $I$ want you to leave this room and Your guests are waiting for you can both be indirect requests that the hearer should leave a certain room, but only the former, which is conventionalized, and not the latter, which is not conventionalized, may be introduced by the verb request in a context of direct quotation: "I want you to leave this room", he requested is acceptable, whereas "Your guests are waiting for you", he requested is unacceptable. The problem, however, is that the author's generalization (which the paper would anyway leave entirely unexplained, even if it obtained) does not invariably obtain. On the one hand, an indirect and conventionalized request of a hearer's leave can be effected both by I must now request that you leave this room and by I would now like to request that you leave this room; contrary, however, to what the author's generalization entails, neither of these utterances can be acceptably introduced by the verb request in a context of direct quotation: both "I must now request that you leave this room", he requested and "I would now like to request that you leave this room", he requested are unacceptable. On the other hand, there can be indirect and non-conventionalized requests of a hearer's leave - for example, I don't want your guests to wait for you any longer - that, contrary to what the author's generalization entails, can be acceptably introduced by the verb request in contexts of direct quotation - for example: Mary asked John if there was anything he wanted her to do. "I don't want your guests to wait for you any longer", he requested. The upshot is, then, that the possibility or impossibility of acceptably introducing a direct quotation of a given utterance by a given illocutionary verb cannot be systematically correlated with the conventionalized or non-conventionalized character the utterance's ability to indirectly imple- 
ment illocutionary acts named by that illocutionary verb.

The paper by Jacques Moeschler ("Speech act theory and the analysis of conversations") is a highly condensed description of the itinerary of a Genevastyle conversation analyst who, it seems, was initially fairly confident about the utility of speech act notions in constructing a model of conversational structure, has subsequently become rather skeptical about the possibility, or even the intelligibility, of constructing such a model — partly, though not exclusively, under the influence of Searle's (1986b) conjecture that conversations do not have an intrinsic structure to be modeled, whether in speech act theoretic or in non-speech act theoretic terms - , and has finally decided to place his bets on relevance theory (Sperber and Wilson 1986), not in the hope of modeling an intrinsic structure that conversations probably don't have but in the hope of showing that conversational structure is a purely epiphenomenal outcome of speakers' and hearers' attempts to interpret each other's vocalizations in accordance with the principle of relevance. This might have been an interesting itinerary for Moeschler to have followed, but those curious about it would be well advised to consult his various publications that the paper summarizes rather than the paper itself. The accounts of the itinerary's abrupt changes of direction are far too brief; the terminology is often idiosyncratic (for example, "pragmatic theory" and "relevance theory" are used as synonyms); the formulation of central claims is often insufficiently precise (for example, the author's currently favored position on the relation between sequencing phenomena and interpretation phenomena is supposed to be conveyed both by the claim that "the sequencing problem is part of the interpretation problem" (p.250) and by the claim that "the sequencing problem is equivalent to the interpretation problem" (p.258), although these two claims are not equivalent, on a normal understanding of their terms); and, last but not least, the identity of the language in which the paper is written is often unclear (for example, there is no English verb 'explicit' as there is a French verb 'expliciter', but the paper, though apparently written in English, contains word strings like the following: "The first purpose of this paper is to explicit the divergence between $[\mathrm{x}]$ and $[\mathrm{y}]$ about $[z] "$ (p.239)).

Marc Dominicy and Nathalie Franken begin their paper ("Speech acts and relevance theory") by warning that it will not deliver what its title would appear to promise - namely, a comprehensive examination of relevance-theoretic claims about the analysis of speech acts - , and they indeed appear to be unaware of an important study by Bird (1994) that, having taken the first steps towards such an examination, has reached results that, if taken into account, 
would help placing their investigations in a proper perspective. Nevertheless, the more restricted goal that their paper primarily pursues - that of evaluating the relevance-theoretic analysis of the imperative mood - is expertly and insightfully accomplished. Since the relevance-theoretic analysis in question was originally presented as an attempt to overcome insuperable problems that a speech act theoretic conception of the imperative mood would allegedly face, the authors' examination has two sub-goals: That of showing that a particular version of speech act theory can in fact account, if appropriately deployed, for most of the uses of imperatives that, according to relevance theorists, speech act theories would be unable to uniformly handle; and that of showing that the alternative account of the imperative mood that relevance theorists have themselves proposed fails, upon closer examination, to give a satisfactory account of most of the uses of imperatives they have set out to cover. The observations and arguments that the authors offer while pursuing each of these sub-goals are unfailingly interesting. The paper, therefore, should supply appropriate material for discussion both to relevance theorists and to speech act theorists preoccupied with the analysis of mood - although the latter might happen to know, having read Harnish (1994), that a version of speech act theory more parsimonious than the one that the authors use has already offered a unifying account of imperatives that sidesteps most of the relevance theoretic objections.

I will conclude with Daniel Vanderveken's paper, which opens the V\&K collection. Upon reading its title ("Universal grammar and speech act theory"), readers might form the expectation that its forty pages will contain some kind of discussion of the question whether speech act theoretic notions should or could be incorporated into contemporary Chomskyan syntactic theory. In fact, the paper offers nothing of the sort, and is entirely unrelated to the few recent works in the Chomskyan tradition (see, for example, Culicover 1992; Han 2000; Krifka 2001; Haegeman 2003) that explicitly rely on illocutionary notions in describing grammatical phenomena. Rather, the author's two main goals are (a) to give an informal exposition of some ideas of the system of illocutionary logic that was officially presented in Searle and Vanderveken (1985) as a formalization of some aspects of Searle's theory of speech acts, and (b) to suggest how some elements of that system could be used in reformulating Grice's theory of conversational implicatures. (A parallel goal appears to be the expression of the author's recently acquired opinion that, though originally unrelated to any sort of Kantianism, illocutionary logic might be viewed as a kind of vindication of Kantian transcendentalism; that opinion, however, cannot be seriously considered in the form in which it is expressed, not only because its exposition 
completely and unaccountably ignores the work of Karl-Otto Apel, which is the most sustained contemporary attempt at a transcendentalist interpretation of speech act theoretic ideas (see, for example, the papers recently collected in Apel 1994), but mainly because, to the minimal extent to which it is defended by the author, it reveals quite fundamental misunderstandings of basic Kantian notions. For example, although Vanderveken claims that "illocutionary logic is transcendental in the sense of Kant" (p.36), his main way of substantiating that claim consists in attaching the label "transcendent" (p.26, p.35, p.36, p.37, p. 45, p. 46) to every single thesis of illocutionary logic that he repeats, without ever realizing something that even beginning students of Kant know, namely, that the terms "transcendent" and "transcendental" have radically different meanings in Kant's system and that, in particular, if something is 'transcendent', then, according to Kant, not only it could not possibly be 'transcendental', but would lie altogether outside the limits of possible thought.) Vanderveken's contributions to the topics listed under (a) and (b) above will be examined in that order.

Considering that, in the nearly twenty years since the official presentation of illocutionary logic, Vanderveken has been its only promoter, the paper's attempt to provide a summary exposition of some of the logic's main ideas might be expected to be, if not particularly exciting, at least reasonably accurate. It turns out, however, that it is not even that. For one thing, the official presentation, unlike Vanderveken's summary, does not attempt to create the illusion that illocutionary logic is a contribution to Kantian philosophy (it does not, for example, contain the obviously untrue claim that the axiomatically introduced 'five illocutionary points' have been established through some kind of "transcendental deduction" (p.61)), nor does it attempt to create the illusion that illocutionary logic is a contribution to generative grammar (it does not, for example, indulge in the gratuitous activity of baptizing illocutionary points "material linguistic universals" (p.32) and operations on illocutionary forces "formal linguistic universals" (p.35)) - notice, incidentally, that if, as the above characterizations jointly imply, illocutionary points were both 'material linguistic universals' and 'transcendentally deducible' entities, it would follow that one could discover material linguistic universals just by means of transcendental deductions, which is, I believe, as grotesque a claim as one could manage to make either about material linguistic universals or about transcendental deductions. For another thing, the official presentation, unlike Vanderveken's summary, generally avoids the practice of presenting intelligible theses as if their acceptance required the acceptance of unintelligible premises. Limitations 
of space allow mention of just two examples. At one point Vanderveken claims that, according to illocutionary logic, the "imperative sentence Please, help me! truth conditionally entails the declarative sentence You can help me" (p.48); illocutionary logic, however, does not officially endorse the incoherent idea that imperative sentences, even though they do not have truth conditions, truth conditionally entail certain other sentences that do have truth conditions; what it endorses is the unsurprising claim that if certain statements about imperatives are true, then certain other statements about imperatives must also be true. For example, if it is true that, in order to comply with the imperative Please, help $m e$ !, the hearer must help the speaker, then it also has to be true that, in order to comply with the same imperative, the hearer must have the ability to help the speaker - simply because it is logically impossible to provide help without having the ability to provide help. And although what illocutionary logic would actually claim about this and similar examples is infinitely less innovative than Vanderveken's summary suggests, it is the only thing that it could claim without lapsing into the kind of incoherence that the summary exemplifies. At another point Vanderveken claims that illocutionary logic can "predict and explain why we are all able to infer from the premise Please, give me a glass of red or white wine! the conclusion Please, give me a glass of wine?" (p. 50); illocutionary logic, however, does not officially endorse the questionably intelligible idea that, given an imperative sentence uttered by a speaker, we can 'infer' that the same speaker has uttered certain other imperative sentences that he has not in fact uttered; what it endorses is the unsurprising claim that, given a statement describing what a speaker has done in uttering an imperative sentence, certain other statements necessarily follow. For example, if it is true that, in uttering a certain imperative sentence, a speaker has attempted to obtain wine that is either red or white, then it must also be true that the same speaker, in uttering the same imperative sentence, has attempted to obtain wine - simply because it is logically impossible to attempt to obtain wine that is either red or white without at the same time attempting to obtain wine. And although, again, the realization that illocutionary logic ultimately deals with inferential relations between certain kinds of statements makes it far less original than Vanderveken's summary suggests, it fortunately makes it far less incredible than the same summary implies. Finally, the official presentation of illocutionary logic is written in readily interpretable English, whereas Vanderveken's summary is written in a kind of English whose interpretation requires the possession of some unnatural abilities (for example, the ability to read "empiric" (p.61) and understand 'empirical', to read "disambiguous" (p.30) and understand 'un- 
ambiguous', to read "insatisfaction" (p.60) and understand 'non-satisfaction', to read "I use to be" (p.52) and understand 'I used to be', etc). It seems to me, then, that the official presentation of illocutionary logic is a much better source to consult in order to find out just what the theses of that logic are (and also, incidentally, just how unoriginal many of these theses are, when they are true) than the inaccurate and misleading summary supplied by Vanderveken's contribution.

Coming, finally, to Vanderveken's suggestions as to how (his version of) illocutionary logic could lead to an improved reformulation of Grice's theory of conversational implicatures (see Grice 1975 and the relevant papers reprinted in Grice 1989), it seems to me that the suggestions are seriously misguided both in what they assume and in what they propose. Vanderveken accepts that Grice's theory is unproblematic as far as implicatures associated with assertive utterances are concerned, but is worried that the theory is not equipped to deal with implicatures associated with non-assertive utterances, and so he proposes generalized reformulations of Gricean conversational maxims in illocutionary terms, believing that these reformulations will make the maxims capable of accounting not only for implicatures associated with assertive utterances but also for implicatures associated with non-assertive (in particular, directive) utterances. To cite the one reformulation that is sketched in some detail, Grice's maxim of quality should, according to Vanderveken, be reformulated as, "Let the illocutionary act that you mean to perform be felicitous in the context of your utterance" (p.53), where an illocutionary act is defined as felicitous in a context of utterance just in case it is "successful, non-defective and satisfied" (p.53) in that context. It is Vanderveken's belief that, applied to the special case of assertive utterances, the generalized formulation will engender exactly what Grice's original quality maxim was demanding, and will thus contribute in the well known Gricean way to the explanation of assertively induced implicatures; but the generalized formulation of the maxim will also be applicable, Vanderveken contends, to all kinds of non-assertive utterances (in particular, to directive utterances), and it will thus make possible the construction of analogous explanations non-assertively induced implicatures as well. Now, Vanderveken's entirely undefended assumption that, as far as assertively induced implicatures are concerned, the Gricean explanations are unproblematic is, after so many years of critical attention devoted to the Gricean approach, difficult to believe, and can only be responded to by referring him to, say, Wayne Davis's recent book (Davis 1998), where many of the severe conceptual and empirical problems that the Gricean approach faces are ably analyzed. But even assuming that the 
Gricean approach is valid for assertively induced implicatures, Vanderveken's claim that his proposed generalization of the Gricean maxims can successfully account for both assertively and non-assertively induced implicatures is demonstrably mistaken.

Recall that Vanderveken's generalized maxim of quality requires that illocutionary acts should be felicitous in the context of utterance, and that the notion of 'felicity' involved is explicated by specifying that the illocutionary acts in question should be successful, non-defective and satisfied. Now, according to illocutionary logic, an assertive illocution is satisfied when it is true, whereas a directive illocution is satisfied when it is complied with (that is, when it is obeyed if it is an order, when it is followed if it is a suggestion, when it is granted if it is a request, etc). Consequently, applied to assertive utterances, the generalized maxim of quality entails that the assertive illocutions expressed by these utterances should be true - which, Vanderveken supposes, is exactly what, according to Grice, hearers would have to assume in order to be in a position to calculate many assertively induced implicatures. Grice, however, was not claiming that, in order to calculate these assertively induced implicatures, the hearer should take the speaker's assertions to be true, but merely that he should take these assertions to be believed by the speaker to be true. And Grice was, of course, quite right in doing so, since, if he were to adopt Vanderveken's requirement, he would be quite unable to derive a large number of assertively induced implicatures that his own requirements do allow him to derive. It is clear, for example, that a speaker who answers the question, Where is Mary?, by the assertion, Mary's car is parked outside Helen's house, can successfully implicate that Mary is probably inside Helen's house, even if his hearers happen to know that his assertion is factually incorrect (even if they know, for example, that the car to which the speaker purports to be referring by the phrase Mary's car is, unbeknownst to the speaker, not Mary's but someone else's car). Grice would have no difficulty in deriving the implicature in that context, since all that, according to him, the hearers would need to assume for their calculations is, on the one hand, that the speaker believes, no matter how mistakenly, that it is Mary's car that is parked outside Helen's house, and, on the other, that he is trying to be cooperative in his answers; but Vanderveken could not possibly derive the implicature in the same context, since his generalized maxim would require the hearers not only to take the speaker to be sincere in his assertions but also to take him not to be mistaken in his assertions (for it is only by taking the speaker not to be mistaken, and not merely by taking him to be sincere, that they could take his assertions to be true, and not merely believed by him to be 
true); and since a huge number of implicatures are communicated through assertions that, though known to be sincerely made, may also be known to be factually incorrect, there is a huge number of assertively induced implicatures that can be easily derived by Grice's original quality maxim but cannot possibly be derived by Vanderveken's generalized quality maxim. So, contrary to what Vanderveken supposes, his generalized maxim does not even succeed in recapturing Grice's account of assertively induced implicatures.

The situation is just as bad, however, when the generalized quality maxim, in the course of Vanderveken's attempt to explain something that Grice never attempted to explain, namely how non-assertively induced implicatures are calculated, is applied to directive utterances. For, applied to directive utterances, the generalized quality maxim requires that the directive illocutions expressed by such utterances should be felicitous; and this, given Vanderveken's definition of felicity, entails that the directive illocutions in question should be satisfied (that is, complied with). Assuming, then, that, as Vanderveken explicitly states, a major source of non-assertively induced implicatures is the hearer's hypothesis that each one of the conversational maxims (and so, the generalized quality maxim) has been respected by the directive illocutions communicating these implicatures, it follows that no such implicatures could be derived from any directive utterance unless the hearer was taking the directive illocution expressed by such an utterance to have respected the generalized quality maxim by having been felicitous (and so, by having been complied with). But this amounts to saying that the addressee of a directive utterance cannot derive an implicature communicated by that directive utterance unless he takes himself to have complied with that directive utterance. And that consequence is so obviously absurd that no theory of implicatures that generates it has any chance of being accepted. Suppose, for example, that, in response to a speaker A's assertive utterance, I wasn't able to find Mary in Paris, a speaker B, who had previously asked A to find Mary and who still wants A to find Mary, produces the directive utterance Go to Rome!, thereby implicating that A may be able to find Mary in Rome. On Vanderveken's account, A will not be able to calculate what B implicates unless he takes B's directive utterance to have respected the quality maxim, and so to have been felicitous. But, on Vanderveken's account of felicity, A cannot take B's directive utterance to have been felicitous unless he takes it to have been satisfied (that is, complied with). And since B's directive utterance cannot be supposed to have been complied with unless A is supposed to have actually gone to Rome, it follows that, according to Vanderveken, A cannot as much as understand what B implicates by saying Go to Rome! unless 
he takes himself to have actually gone to Rome. But that consequence is clearly absurd: In order to understand that, when uttered in response to I wasn't able to find Mary in Paris, the imperative Go to Rome! can successfully implicate that its addressee may be able to find Mary in Rome, it is certainly not necessary to assume that either its addressee or anyone else has ever gone or will ever go to Rome. And any theory that, like Vanderveken's, is constrained to deny this simple fact, can hardly be considered, let alone accepted, as a defensible account of nonassertively induced implicatures. Adding to this that, for reasons already explained, Vanderveken's theory cannot supply a defensible account of even assertively induced implicatures, it is difficult to avoid the conclusion that Vanderveken's attempted employment of illocutionary logic as a basis for reconstructing Grice's theory of conversational implicatures is an unmitigated failure.

It will come as no surprise, given all the above remarks, that my opinion on the $\mathrm{V} \& \mathrm{~K}$ volume is very far from being positive: With the exception of just two papers (the one by Yamada and the one by Dominicy and Franken), the volume makes no appreciable contribution to the advancement of research on any speech act theoretic topic, and its extreme lack of editorial care about linguistic matters risks embarrassing even the least demanding among its readers (though, obviously, it did not succeed in embarrassing its publishers). Overall, then, the $\mathrm{V} \& \mathrm{~K}$ volume is a sad but clear example of the low standards of argumentation, and of the even lower standards of publication, that are sometimes operative in contemporary pragmatics.

\section{References}

Alston, W.P. 2000. Illocutionary Acts and Sentence Meaning. Ithaca, NY: Cornell University Press. Apel, K.-O. 1994. Selected Essays, Vol.1: Towards a Transcendental Semiotics. Atlantic Highlands, NJ: Humanities Press.

Austin, J.L. 1962. How to do Things with Words. Oxford: Clarendon Press.

Bach, K. and Harnish, R.M. 1979. Linguistic Communication and Speech Acts. Cambridge, MA: The MIT Press.

Bennett, J. 1991. "How do gestures succeed?". In E. Lepore and R. Van Gulick (eds), John Searle and his Critics. Oxford: Blackwell, 3-15.

Brandom, R. B. 2000. Articulating Reasons: An Introduction to Inferentialism. Cambridge, MA: Harvard University Press.

Binkley, T. 1979. "The principle of expressibility". Philosophy and Phenomenological Research 39: 307-325.

Bird, G.H. 1994. "Relevance theory and speech acts". In Tsohatzidis (ed), pp. 292-311.

Burge, T. 1979. "Individualism and the mental”. Midwest Studies in Philosophy 4: 73-121. 
Chalmers, D. J. 1996. The Conscious Mind: In Search of a Fundamental Theory. Oxford: Oxford University Press.

Culicover, P.W. 1992. "English tag questions in Universal Grammar”. Lingua 88: 193-226.

Davidson, D. 1980. Essays on Actions and Events. Oxford: Clarendon Press.

Davis, W.A. 1998. Implicature: Intention, Convention and Principle in the Failure of Gricean Theory. Cambridge: Cambridge University Press.

Devitt, M. 1990. “Meanings just ain't in the head”. In G. Boolos (ed), Meaning and Method: Essays in Honor of Hilary Putnam. Cambridge: Cambridge University Press, 79-104.

Devlin, K. 1991. Logic and Information. Cambridge: Cambridge University Press.

Dreyfus, H.L. 2001. "Phenomenological description versus rational reconstruction". Revue Internationale de Philosophie 55: 181-196.

Faigenbaum, G. 2001. Conversations with John Searle. Montevideo: Libros en Red.

Fitzpartick, D. 2003. "Searle and collective intentionality: The self-defeating nature of internalism with respect to social facts". American Journal of Economics and Sociology 62: 45-66.

Forguson, L.W. 1973. "Locutionary and illocutionary acts". In G. Warnock (ed), Essays on J. L. Austin. Oxford: Clarendon Press, 160-185.

Frye, M. 1976. “On saying”. American Philosophical Quarterly 13: 123-127.

Furberg, M. 1971. Saying and Meaning: A Main Theme in J.L. Austin's Philosophy. Oxford: Blackwell.

Grice, P. 1957. “Meaning”. The Philosophical Review 66: 377-388.

Grice, P. 1975. "Logic and conversation". In P. Cole and J.L. Morgan (eds), Syntax and Semantics, Vol. 3: Speech Acts, New York: Academic Press, 41-58.

Grice, P. 1989. Studies in the Way of Words. Cambridge, MA: Harvard University Press. Griffiths, L. 1969. “The logic of Austin's locutionary subdivision”. Theoria 35: 204-214. Haegeman, L. 2003. “Conditional clauses: external and internal syntax”. Mind and Language 18: 317-339.

Han, C.-H. 2000. The Structure and Interpretation of Imperatives: Mood and Force in Universal Grammar. New York: Garland.

Harnish, R. M. 1994. “Mood, meaning and speech acts”. In Tsohatzidis (ed), pp.407-459.

Holdcroft, D. 1978. Words and Deeds: Problems in the Theory of Speech Acts. Oxford: Clarendon Press.

Humberstone, L. 1992. "Direction of fit". Mind 101: 59-83.

Koepsell, D. and Moss, L. (eds). 2003. John Searle's Ideas about Social Reality: Extensions, Criticisms, and Reconstructions. Oxford: Blackwell.

Krifka, M. 2001. “Quantifying into question acts”. Natural Language Semantics 9: 1-40. Lepore, E. and van Gulick, R. (eds). 1991. John Searle and his Critics. Oxford: Blackwell. Levine, J. 2001. Purple Haze: The Puzzle of Consciousness. Oxford: Clarendon Press.

McCulloch, G. 1995. The Mind and its World. London: Routledge.

Meggle, G. (ed). 2002. Social Facts and Collective Intentionality. Frankfurt: Dr. HanselHohenhausen AG.

Mulligan, K. (ed). 1987. Speech Act and Sachverhalt: Reinach and the Foundations of Realist Phenomenology. Dordrecht: Martinus Nijhoff.

Preston, J. and Bishop, M. (eds). 2002. Views into the Chinese Room: New Essays on Searle and Artificial Intelligence. Oxford: Clarendon Press. 
Putnam, H. 1975. “The meaning of 'meaning"'. In K. Gunderson (ed), Language, Mind and Knowledge, Minneapolis, MN: University of Minnesota Press, 131-193.

Récanati, F.1980. “Qu'est-ce qu'un acte locutionnaire?”. Communications 32: 190-215.

Récanati, F. 1981. Les Enoncés performatifs: Contribution à la pragmatique. Paris: Minuit.

Récanati, F. 1987. Meaning and Force: The Pragmatics of Performative Utterances. Cambridge: Cambridge University Press.

Récanati, F. 2003. “The limits of expressibility”. In B. Smith (ed), John Searle. Cambridge: Cambridge University Press, 189-213.

Robinson, J. 1974. "The individuation of speech acts". The Philosophical Quarterly24: 316-336.

Ruben, D.-H. 1997. "John Searle's The Construction of Social Reality”. Philosophy and Phenomenological Research 57: 443-447.

Sadock, J.M. 1994. “Toward a grammatically realistic typology of speech acts". In Tsohatzidis (ed), pp.393-406.

Schiffer, S. R. 1972. Meaning. Oxford: Clarendon Press.

Schuhmann, K. and Smith, B. 1990. "Elements of speech act theory in the philosophy of Thomas Reid”. History of Philosophy Quarterly 7: 47-66.

Searle, J.R. 1968. "Austin on locutionary and illocutionary acts". The Philosophical Review 77: 405-424.

Searle, J.R. 1969. Speech Acts: An Essay in the Philosophy of Language. Cambridge: Cambridge University Press.

Searle, J.R. 1975. “A taxonomy of illocutionary acts”. In K. Gunderson (ed), Language, Mind and Knowledge. Minneapolis, MN: University of Minnesota Press, 344-369.

Searle, J.R. 1979. Expression and Meaning: Studies in the Theory of Speech Acts. Cambridge: Cambridge University Press.

Searle, J.R. 1980. "Minds, brains, and programs". The Behavioral and Brain Sciences 3: 417-424.

Searle, J. R. 1983. Intentionality: An Essay in the Philosophy of Mind. Cambridge: Cambridge University Press.

Searle, J.R. 1984. Minds, Brains and Science: The 1984 Reith Lectures. Cambridge, MA: Harvard University Press.

Searle, J.R. 1986a. "Meaning, communication, and representation". In R. Grandy and R. Warner (eds), Philosophical Grounds of Rationality: Intentions, Categories, Ends. Oxford: Clarendon Press, 209-226.

Searle, J.R.1986b. "Notes on conversation". In D.G. Ellis and W.A. Donohue (eds), Contemporary Issues in Language and Discourse Processes. Hillsdale, NJ: Lawrence Erlbaum Associates, 7-19.

Searle, J. R. 1989. "How performatives work”. Linguistics and Philosophy 12: 535-558.

Searle, J.R. 1990. "Consciousness, explanatory inversion, and cognitive science". The Behavioral and Brain Sciences 13: 585-596.

Searle, J.R. 1991. "Intentionalistic explanations in the social sciences". Philosophy of the Social Sciences 21: 332-344.

Searle, J.R. 1992. The Rediscovery of the Mind. Cambridge, MA: The MIT Press.

Searle, J.R. 1995. The Construction of Social Reality. London: Allen Lane.

Searle, J.R. 1997. The Mystery of Consciousness. London: Granta Books.

Searle, J.R. 1999. Mind, Language, and Society: Doing Philosophy in the Real World. London: Weidenfeld and Nicolson. 
Searle, J. R. 2001. Rationality in Action. Cambridge, MA: The MIT Press.

Searle, J. R. 2002. Consciousness and Language. Cambridge: Cambridge University Press.

Searle, J. R. and Vanderveken, D. 1985. Foundations of Illocutionary Logic. Cambridge: Cambridge University Press.

Siebel, M. 2001. "Searle's representing account of illocutionary acts and its weak spots". Acta Philosophica Fennica 69: 97-111.

Smith, B. 1990. "Toward a history of speech act theory". In A. Burkhardt (ed), Speech Acts, Meaning and Intentions: Critical Approaches to the Philosophy of John Searle. Berlin: Walter de Gruyter, 29-61.

Smith, B. (ed). 2003. John Searle. Cambridge: Cambridge University Press.

Sperber, D. and Wilson, D. 1986. Relevance: Communication and Cognition. Oxford: Blackwell.

Strawson, P. F. 1964. "Intention and convention in speech acts". The Philosophical Review 73: 439-460.

Strawson, P. F. 1973. “Austin and 'locutionary meaning”". In G. Warnock (ed), Essays on J.L. Austin, Oxford: Clarendon Press, 46-68.

Stroll, A. 1989. "What water is, or back to Thales". Midwest Studies in Philosophy 14: 258-274.

Stroll, A. 1998. "Proper names, names, and fictive objects". The Journal of Philosophy 95: 522-534.

Stroll, A. 2000. Twentieth-Century Analytic Philosophy. New York: Columbia University Press. Thagard, P. 2000. Coherence in Thought and Action. Cambridge, MA: The MIT Press.

Thalos, M. 2003. "Searle's Foole: How a constructionist account of society cannot substitute for a causal one". American Journal of Economics and Sociology 62: 105-122.

Thau, S. 1972. "The distinction between rhetic and illocutionary acts". Analysis 32: 177-183.

Tsohatzidis, S.L. 1993. "Emotional states and linguistic events: a study of conceptual misconnections". Pragmatics \& Cognition 1: 229-242.

Tsohatzidis, S.L. (ed). 1994. Foundations of Speech Act Theory: Philosophical and Linguistic Perspectives. London: Routledge.

Tuomela, R. 2002. Philosophy of Social Practices: A Collective Acceptance View. Cambridge: Cambridge University Press.

Turner, S. P. 1999. “Searle's social reality”. History and Theory 38: 211-231.

Viskovatoff, A. 2002. "Searle's Background”. Journal of Economic Methodology 9: 65-80.

Viskovatoff, A. 2003. "Searle, rationality and social reality". American Journal of Economics and Sociology 62: 7-44.

Wettersten, J. 1998. “The analytic study of social ontology: breakthrough or cul-de-sac?". Philosophy of the Social Sciences 28: 132-151.

Author's address

Savas L. Tsohatzidis

Department of Linguistics

Faculty of Philosophy

Aristotle University of Thessaloniki

GR-54124 Thessaloniki

Greece

Email: savasts@lit.auth.gr 


\section{About the author}

Savas L. Tsohatzidis is Professor of General Linguistics and the Philosophy of Language at Aristotle University of Thessaloniki. He was the editor of Foundations of Speech Act Theory: Philosophical and Linguistic Perspectives (1994) and has published in Mind, Analysis, Erkenntnis, Linguistics and Philosophy, Linguistics, Studies in Language, Language Sciences, Syntax, Cognitive Linguistics, Language and Communication, Lingustische Berichte, Word, and other academic journals. 


\section{Errata}

The following corrections should be made in reading Savas L. Tsohatzidis' Review Article "Voices and noises in the theory of speech acts", published in P\&C, volume 12, No. 1:

1. On page 116, line 4 from bottom, one reads "citing as the basis the anti-theoretical view" instead of "citing as the basis of the anti-theoretical view".

2. On page 144, line 7 from bottom, one reads "explanations non-assertively induced implicatures" instead of "explanations of non-assertively induced implicatures".

We apologize for these misprints. 